\title{
Molecular Materials and Devices: Developing New Functional Systems Based on the Coordination Chemistry Approach
}

\author{
Henrique E. Toma
}

Instituto de Química, Universidade de São Paulo, CP 26077, 05513-970 São Paulo - SP, Brazil

\begin{abstract}
Neste limiar da era nanotecnológica, o planejamento molecular dos materiais e os estudos de moléculas isoladas estão abrindo imensas possibilidades no emprego de sistemas moleculares em dispositivos eletrônicos e fotônicos, bem como em aplicações tecnológicas baseadas em propriedades de chaveamento ou reconhecimento molecular. Com esse escopo, os químicos inorgânicos em particular, podem aplicar com vantagens as estratégias proporcionadas pela química de coordenação, para construir nanomateriais funcionais que permitam a exploração das propriedades dos centros metálicos e das características dos ligantes presentes. A química de coordenação também oferece recursos eficientes na auto-montagem de nanoestruturas, baseadas na especificidade da interação metal-ligante e nas características estereoquímicas dos complexos. Diversos materiais moleculares gerados a partir de compostos inorgânicos e metal-orgânicos são focalizados neste artigo, com ênfase em novas porfirinas e porfirazinas supramoleculares, clusters e complexos metálicos. Tais sistemas também são enfocados sob o ponto de vista de suas aplicações em catálise, sensores e dispositivos moleculares.
\end{abstract}

At the onset of the nanotechnology age, molecular designing of materials and single molecule studies are opening wide possibilities of using molecular systems in electronic and photonic devices, as well as in technological applications based on molecular switching or molecular recognition. In this sense, inorganic chemists are privileged by the possibility of using the basic strategies of coordination chemistry to build up functional supramolecular materials, conveying the remarkable chemical properties of the metal centers and the characteristics of the ancillary ligands. Coordination chemistry also provides effective self-assembly strategies based on specific metal-ligand affinity and stereochemistry. Several molecular based materials, derived from inorganic and metal-organic compounds are focused on this article, with emphasis on new supramolecular porphyrins and porphyrazines, metal-clusters and metal-polyimine complexes. Such systems are also discussed in terms of their applications in catalysis, sensors and molecular devices.

Keywords: molecular nanotechnology, supramolecular chemistry, molecular devices, molecular films, sensors

\section{Introduction}

Molecular nanotechnology is an important branch of the nanosciences, exhibiting strong chemical appeal, besides encompassing most of the exciting aspects of nanomaterials, nanobiology and nanoelectronics. In a historical perspective, it was Richard Feynman, ${ }^{1}$ in his 1959 talk "There's Plenty of Room at the Bottom" who first considered the possibility of processing the information at the atomic level, calling the attention for the new universe hidden in the nanodimensional space. In 1965 , Arthur von Hippel $^{2}$ proposed the bottom up approach to materials design, in his book "The Molecular Designing

\footnotetext{
* e-mail: henetoma@iq.usp.br
}

of Materials and Devices". In the following years, the molecular approach expanded considerably, from the development of chemical vapor deposition, sol-gel and related processes, leading to dramatic changes in electronics and materials design.

Nowadays, the future of the technology unquestionably bears on the progress of the materials science. Consequently, with the rise of molecular nanotechnology, molecular materials are becoming a major focus of interest for the design of nanostructures and devices. $^{3-20}$ In fact, functional nanostructured molecular materials are being currently pursued in the academy and industries, relying on the bottom up approach, as envisaged by Erix Drexler, ${ }^{3}$ but using molecular building blocks and supramolecular chemistry as tools. ${ }^{5-20}$ 
Supramolecular chemistry provides, perhaps, the most important strategy toward molecular nanotechnology. It has been defined as the chemistry beyond the molecule. ${ }^{5}$ Its essence arises from the special way the different molecules interact, exchanging information and creating organized structures. In the supramolecular design, molecular building blocks incorporating suitable functional groups are specially devised in order to promote their effective coupling by means of hydrogen bonding, hydrophobic or/and electrostatic interactions, or metal ion coordination. The last point, here referred as the coordination chemistry approach, has been systematically exploited by our group since the last decade. It is increasingly being employed in the development of supramolecular systems, due to its many advantages, such as the self-assembly character of the metal-ligand complexation; the control of selectivity based on simple acid-base principles, and the introduction of a variety of structural, electronic, energetic and kinetic properties. Such important properties convey an exceptional functionality gain for the nanostructured materials containing metal complexes. Now, going back to an earlier expectation, reported in 1991 by the occasion of the National Meeting of the Brazilian Chemical Society, ${ }^{7}$ this article will focus mainly on the exciting perspectives of the coordination chemistry approach toward molecular nanotechnology.

\section{A Chemical Route for Molecular Nanotechnology}

Chemistry provides the starting point in the route for molecular nanotechnology shown in Figure 1, creating from atoms and molecules, the molecular building blocks (or synthons) for the construction of nanoscale structures, such as nanoparticles, nanolayers and nanotubes. By working out appropriately the assembled nanostructures, an unlimited number of nanostructured materials can be generated, allowing important applications, such as dispersions and coatings, high surface area materials, high performance materials and functional nanodevices.

The coordination chemistry approach has been successfully employed in the self assembly of highly organized structures, such as those resulting from the direct interaction between linear polypyridine polymers and copper(I) ions..$^{5,19}$ Nanoporous materials have been generated from discrete molecular building blocks, as exemplified by the series of nanoscale cavity-containing coordination compounds, reported by Belanger et al.. ${ }^{8}$ In this particular aspect, the coordination approach is very effective, circumventing two of the most conventional problems found in solid state chemistry. The first one is

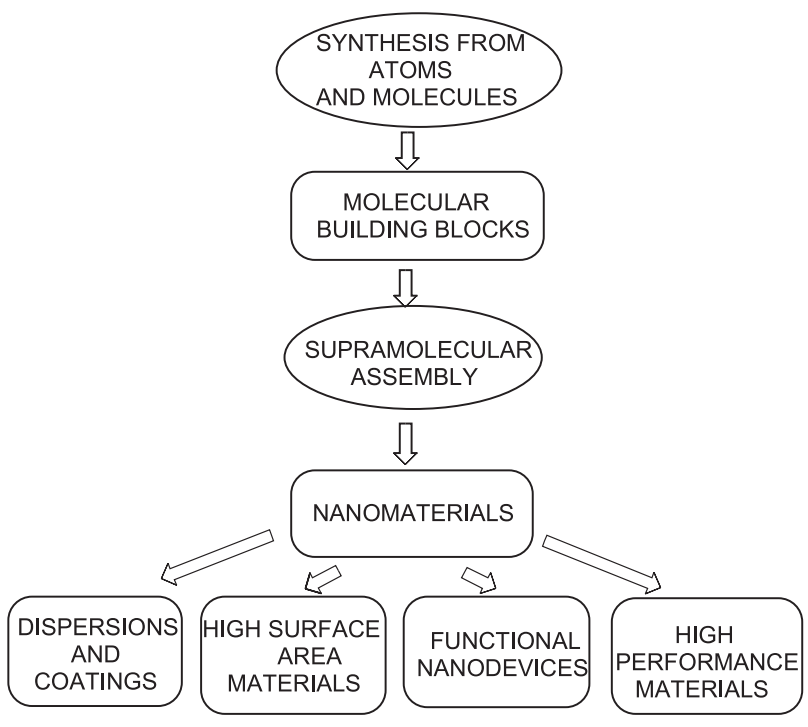

Figure 1. A chemical route for molecular nanotechnology, starting from the synthesis of molecular building blocks, followed by their supramolecular assembly for the design of nanomaterials and devices.

the collapse of the channels upon removal of the solvent from the porous solid. In the molecular nanostructured materials involving bridged coordination compounds, the interactions are usually strong enough to preclude the cavity and channel collapse. The second is the occurrence of multiple intersecting and interpenetrating structures replacing the vacancies in the solids. This is less prone to occur in such nanostructured materials, if intentionally substitution-inert coordination compounds are employed.

Because of their key role, molecular building blocks should be carefully planned in order to generate nanostructured materials. Most of the strategies rely upon the preprogramming of synthons, in order to allow a directed-assembly approach. For instance, in the assembly of square cavity structures (Figure 2), synthons have been employed $^{8}$ consisting of octahedral complexes displaying rigid or semi-rigid bifunctional edges in cis-configuration, a detail which allows them to coordinate sequentially.
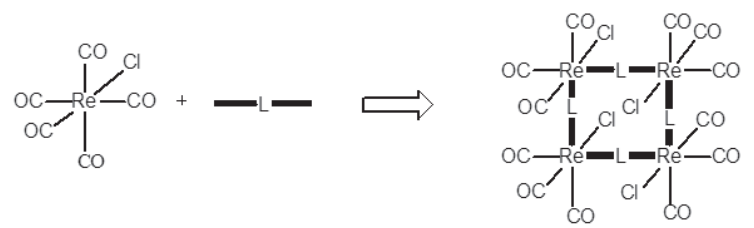

Figure 2. Example of directed assembly of building blocks for molecular materials, where -L- is a bridging ligand, such as pyrazine, 4,4 '-bipyridine and related species.

This type of molecular nanostructured material exhibits a selective size control response when deposited onto 
electrode surfaces, discriminating, by means of amperometric response, the small ferrocene type of ions from typically large redox active species. ${ }^{8}$

\section{Nanoscale Technology}

The development of nanoscale technology is a rather complex subject, which can be focused on, either in terms of a bottom-up (molecular approach) or a top-down (miniaturization) approach. The main reasons behind moving to smaller sizes are the superior physical properties of the nanostructured materials, including the improved mechanical, electronic and/or optical response in molecular timescales, the better efficiency of the precisely engineered micro/nano electronic devices, and more powerful processing and computing performance. Microelectromechanical (MEMS) and microelectronic devices have been designed based on the available lithography processes. Further reduction to the nanoscale dimension, however, will require the use of very short wavelengths, in the ultraviolet and X-ray spectral region, as provided by the Synchroton radiation, implying in the involvement of very sophisticated and expensive equipments.

Nanoparticles combined with polymers can generate a wide variety of nanocomposite materials. Although they are expected to be the first high-scale nanotechnology products to appear in the market, it should be noticed that the modification of the chemical and physical properties of the polymers by using fine particles is not a new fact. For instance, most of the plastic coatings employed in electrical cables already contain large amounts of finely divided inorganic oxides and clays; whereas rubber tires contain a high percentage of carbon black. However, it should be mentioned that the remarkable improvement of the mechanical properties of the plastics by the use of suitable inorganic nanoparticles is attracting more and more investiments in this area. Such nanocomposites are contributing for a better quality and low cost of the containers and recipients, specially for beverages and food. The resistance of the optical glasses is significantly improved by the incorporation of nanoparticles. Also, inorganic nanoparticles are being successfully employed in high quality photographic papers, preventing the diffusion and spreading of the images by concentrating the very small dots of ink at the impact region. The most impressive applications of nanoparticles will be found in cosmetics. Nanoparticles can be used to impart a much better performance for the cosmetic products, such as light scattering control, ultraviolet radiation protection, softness, and coverage.
Molecular machines and devices are being pursued as possible nanosize versions of the microscale components of MEMS and microelectronics. ${ }^{9-20}$ The development of this area has been very impressive, and is moving up to the top end of the miniaturization scale: the single molecule technology. With the aid of scanning probe microscopy (AFM, STM), single atoms and molecules can be precisely imaged and manipulated. Such a positional control allows to connect them to microelectrodes, or suitable circuits, and thus to perform single molecule conduction measurements.

A single molecule can efficiently capture light or electrons, as well as electric or magnetic impulses, and then, processing information. For instance, it can also undergo geometrical changes, such as cis-trans photoisomerization, producing atomic movements under the action of light. Specialized molecules can conduct electron (molecular wires), or pump electrons/photons (photonic pumps). Molecules can also be effective probes for molecular recognition. Combining such many abilities and properties, molecules can be designed to communicate with each other, signalizing this by means of color changes, emission of light and/or sound, release or uptake of protons and ions, etc. They can also be interfaced to a metal wire or fiber optics, for transducing their response into measurable electrical or optical signals. The possibility of changing the molecular properties can be used to convert them into molecular optical or electrical switches. A very interesting case is the ability of some dichalcogenide carbamate esters to undergo reversible light induced tautomerism, generating two enantiomers. The reversible light induced conversion of the two quiral forms can be used to write and read information, in a binary language. This class of optoelectronic molecular materials has been patented as chiropticene ${ }^{\circledR}$ switch, and recently employed in supramolecular opto-electronic architectures, supporting a memory capacity of 2 terabytes, in a device of the size of a cubic inch. ${ }^{21}$ Therefore it is not surprising that smallest nanomachines can be really made up of single molecules, fitted in a suitable supramolecular environment.

\section{Molecular Building Blocks and Supramolecular Chemistry}

Coordination compounds such as those illustrated in Figure 3 have been systematically employed as versatile building blocks for the assembling of symmetric supramolecular structures. ${ }^{7,22,23}$ Such complexes are rather stable and inert, imparting convenient structural characteristics to the supramolecular species, and also a wide variety of functional aspects from their rich chemistry. 
As a matter of fact, ruthenium(II) polypyridine and polypyrazine complexes (Figure 3a) are among the most extensively investigated compounds in the last decades, because of their remarkable photochemical and photophysical properties. ${ }^{24,25}$ Triangular m-oxo-bridged ruthenium-acetate clusters (Figure $3 \mathrm{~b}$ ) provide another interesting class of complexes, displaying strong electronic delocalization, and a series of reversible monoelectronic redox processes in the range of -2.0 to $2.0 \mathrm{~V}$. The behavior of the triangular center can be modulated by the application of potentials, as well as by the nature of the axial ligand. This aspect is particularly interesting, since at very negative potentials, the triangular clusters become strong $\pi$-donor agents, while at the opposite extreme they act as strong $\pi$-acceptor agents. A comprehensive review of the triangular ruthenium clusters has been recently reported. ${ }^{22}$ Iron(II) and ruthenium(II) polyimine complexes (Figure $3 c$ ) functionalized with pyridine bridging groups provide flexible building blocks for supramolecular structures and have also been exploited for molecular recognition purposes. Meso-tetra(4-pyridyl)porphyrins (Figure 3d) are particularly important because of the presence of the biomimetic porphyrin center, which can be further exploited in combination with the several metal complexes, through the bridging pyridine ligand. Finally, the tetrapyridylporphyrazine species (Figure 3e) differ from the corresponding porphyrin analogues, by the presence of the four nitrogen atoms at the meso-position and by the fused pyridine ring.

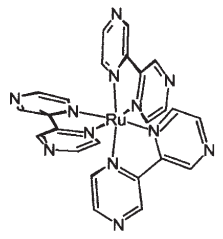

a)

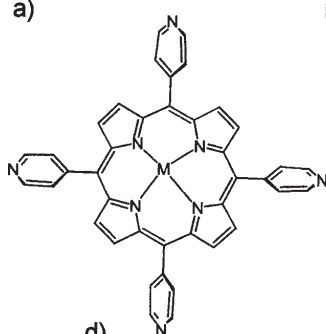

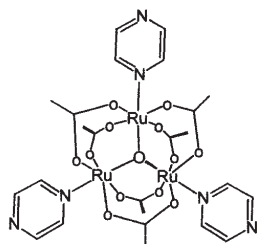

b)
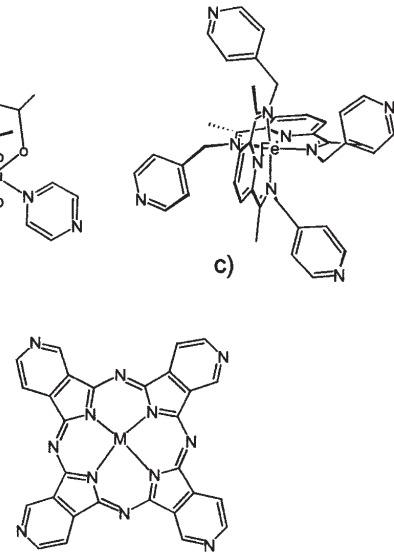

e)

Figure 3. Typical multibridging metal-organic building blocks employed in the generation of functional supramolecular structures based on the coordination chemistry approach.

Combination of such molecular building blocks can be performed by using metal ions as linking elements, but the direct combination usually leads to insoluble, random polymeric materials. A better control can be achieved by employing suitable metal complexes displaying functional groups for selective molecular interactions or for carrying out electrochemical coupling, via electropolymerization reactions, such as $\left[\mathrm{Fe}(\mathrm{CN})_{5}\right]^{3-},\left[\mathrm{RuCl}(\text { bipy })_{2}\right]^{+}$, $\left[\mathrm{RuCl}(\text { phen- } \mathrm{Cl})_{2}\right]^{+}$and $\left[\mathrm{Ru}_{3} \mathrm{O}(\mathrm{Ac})_{6}(\mathrm{py})_{2}\right]^{+}$. The use of such metal complexes attached to the peripheral bridging groups has been proved highly rewarding. In fact, by combining ruthenium(II)-polypyridine complexes and porphyrins or porphyrazines, novel types of supermolecules exhibiting enhanced chemical, electrochemical, photochemical and photophysical properties have been generated. A typical example is shown in Figure 4. Strong hydrophobic interactions allow the packing of the highly symmetric supermolecules into organized molecular layers. By making use of appropriate combinations of electrostatic and $\pi$-stacking effects, functional bilayered structures have been assembled, involving different types of porphyrins and porphyrazines supermolecules. The chemistry of such polymetallic porphyrins has been recently reviewed, ${ }^{25,26}$ and will not be dealt with here. Instead, we will concentrate on the recent progress in the characterization and properties of the molecular materials generated from the supramolecular approach, as well as on their applications in molecular devices.

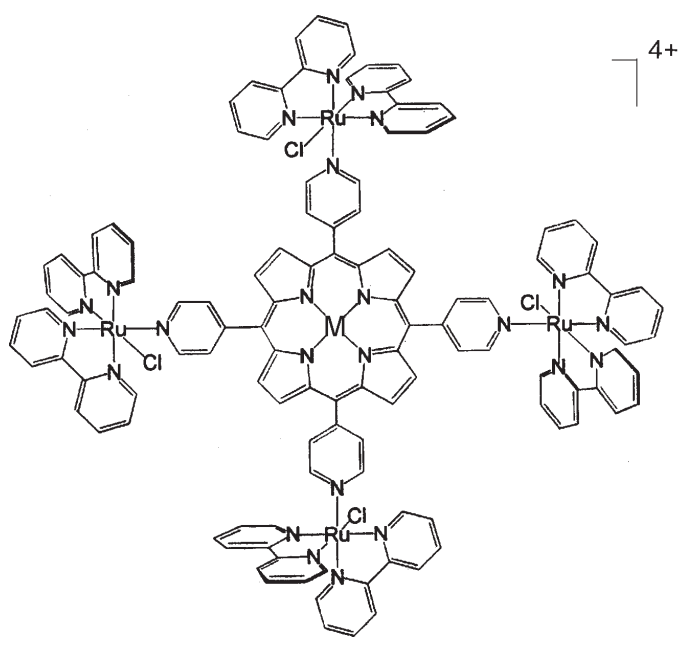

Figure 4. A typical example of symmetric supermolecule derived from meso-tetrapyridyl porphyrin, by attaching four $\left[\mathrm{Ru}(\mathrm{II})(\text { bipy })_{2} \mathrm{Cl}\right]^{+}$complexes at the peripheral pyridine $\mathrm{N}$-atoms.

\section{Proton-Induced Molecular Switching}

The development of molecular switching represents an important issue to be pursued in the design of molecular devices. In the coordination chemistry approach, molecular switching can be conveniently performed by polynuclear complexes containing suitable bridging ligands, capable of modulating the intermetallic electronic interactions. 
This control can be performed by exploiting two crucial factors: the molecular geometry and the electronic properties of the bridge. In this way, switches can be made by chemically or physically changing the molecular conformation or the metal-metal separation, as well as, by tuning the degree of the electronic coupling through the redox and/or acid-base properties of spacer. ${ }^{27-33}$ Another way of controlling metal-metal interactions is based on the differential solvent effects on the metal complexes. ${ }^{34,35}$

A simple and efficient $\mathrm{pH}$-induced molecular "on/off" switching has been recently devised based on a symmetric bridged ruthenium dimer, $\left[\left(\right.\right.$ edta) $\mathrm{Ru}(\mu-\mathrm{L}) \mathrm{Ru}(\text { edta) }]^{\mathrm{n}-}$, where $\mathrm{n}=3$, or 4 , and $\mathrm{L}=$ benzotriazolate ligand, by exploiting its unusual mixed-valence state behavior as a function of the $\mathrm{pH} .{ }^{36}$ Benzotriazole is an $N$-heterocycle possessing three vicinal coordinating $N$-atoms, with the ability to form mono $^{37-39}$ and binuclear complexes ${ }^{40-42}$ with transition metal ions. The chemistry of this type of rutheniumbenzotriazolate complex is characterized by a fluxional coordination model involving the bridging ligand.

Due to the strong metal-metal electronic coupling, the symmetric binuclear complex, $\left[(\right.$ edta $) \mathrm{Ru}(\mu-\mathrm{L}) \mathrm{Ru}(\text { edta) }]^{3-}$ is readily formed from the reaction of $\left[\mathrm{Ru}^{\mathrm{III}}(\mathrm{edta})\left(\mathrm{H}_{2} \mathrm{O}\right)\right]^{-}$ with benzotriazole, even in the presence of an excess of the bridging ligand. ${ }^{36}$ The cyclic voltammograms in aqueous solutions at several $\mathrm{pH}$, show two reversible wave couples, with identical current intensity at any potential scan rate and typical monoelectronic Nernstian behavior, as shown in Figure 5. The redox potentials $\mathrm{E}(1)$ and $\mathrm{E}(2)$ refer to the $\mathrm{Ru}^{\mathrm{III}} \mathrm{Ru}{ }^{\mathrm{III}} / \mathrm{Ru}^{\mathrm{III}} \mathrm{Ru}^{\mathrm{II}}$ and $\mathrm{Ru}^{\mathrm{III}} \mathrm{Ru}^{\mathrm{II}} / \mathrm{Ru}^{\mathrm{II}} \mathrm{Ru}^{\mathrm{II}}$ couples. By decreasing the $\mathrm{pH}$ of the solution, the most evident transformation in the cyclic voltammograms is the progressive decrease of $\Delta \mathrm{E}=\mathrm{E}(1) \mathrm{E}(2)$, from $195 \mathrm{mV}$ (at pH 8.0) to $c a .75 \mathrm{mV}$ (at pH 2.5). The calculated pKa of the bridging benzotriazole ligand is 3.3 . At $\mathrm{pH} 8.0$, a very strong intervalence band appears at $1450 \mathrm{~nm}(\varepsilon=2200$ $\mathrm{mol}^{-1} \mathrm{~L} \mathrm{~cm}^{-1}$ ), exhibiting a rather narrow bandwidth $\left(2900 \mathrm{~cm}^{-1}\right)$ as compared with the theoretical one $\left(3990 \mathrm{~cm}^{-1}\right)$ for a class III system in the Robin-Day categorization of mixed valence systems. ${ }^{43}$ All the data support a strongly coupled mixed-valence system. Below pH 3, the protonation of the bridging ligand decreases dramatically the electronic coupling between the two metal centers, leading to a rather weak and broad intervalence transfer band around $1410 \mathrm{~nm}\left(\varepsilon=185 \mathrm{~mol}^{-1} \mathrm{~L} \mathrm{~cm}^{-1}\right)$.

The rather distinct strengths of electronic coupling for these protonated and deprotonated mixed-valence complexes has been rationalized from a molecular orbital energy/superexchange perspective. ${ }^{43}$ Apart from the structural factor (geometric intermetallic distance), the magnitude of the interaction between the metal ions

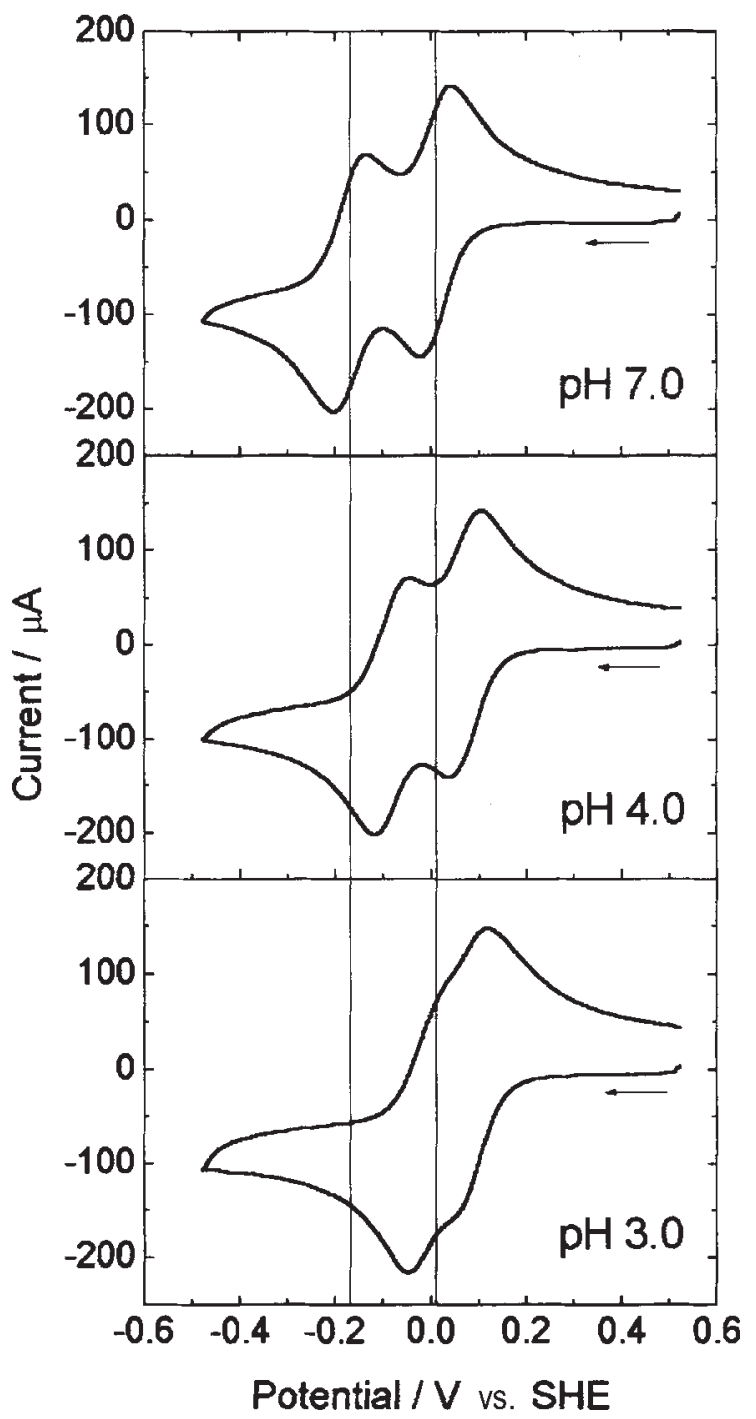

Figure 5. Cyclic voltammograms of $[(\text { edta }) \operatorname{Ru}(\mu \text {-L }) \operatorname{Ru}(\text { edta })]^{3-}$ $5.0 \times 10^{-3} \mathrm{~mol} \mathrm{~L}^{-1}$, in an aqueous solution at several $\mathrm{pH}, \mathrm{I}=0.10 \mathrm{~mol} \mathrm{~L}^{-1}$ $\mathrm{KNO}_{3}$

depends essentially on the mixing between the redox levels of the ruthenium(II,III) ions and the frontier orbitals of the bridging ligand. Unlike pyridine and pyrazine ligands, which have low-lying $\pi$-orbitals, and therefore act as $\pi$-acceptor ligands, the triazolate derivatives are similar to imidazoles and behave as $\sigma / \pi$-donors. ${ }^{44,45}$ This means that the metal-metal electronic communication is governed predominantly by a hole-transfer mechanism. ${ }^{46}$ As a consequence, protonation of the benzotriazolate ligand induces a decrease of its $\pi$-orbital energies, and the interaction between the $\mathrm{d} \pi(\mathrm{Ru})$ and $\pi(\mathrm{btaH})$ orbitals decreases, leading to the lowering of the resonance energy.

In this way, the metal-metal electron coupling can be modulated as a function of the $\mathrm{pH}$, from the protonation/ deprotonation of the intervening benzotriazolate $\left(\mathrm{bta}^{-}\right) /$ benzotriazole (btaH) ligand, providing a striking proton- 
induced molecular switching system as illustrated in Figure 6.

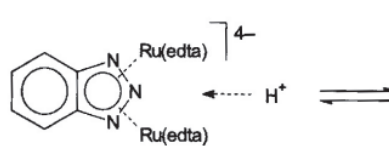

(strong communication)

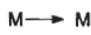

(ON)
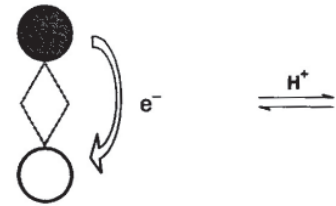

(weak communication)

$M \nrightarrow M$
Figure 6. A reversible, proton-induced molecular switching: protonation of the benzotriazole bridging ligand decreases the extent of metal-metal coupling, and electronic communication in the mixed valence complex.

\section{Molecular Recognition}

Iron(II) polyimine complexes functionalized with bridging groups provide useful building blocks for the generation of supramolecular structures, as exemplified in Figure 7. Such complexes exhibit characteristic red-violet colors, and their low spin configuration results from the exceptional stability of the iron(II)-diimine bonding. ${ }^{47}$

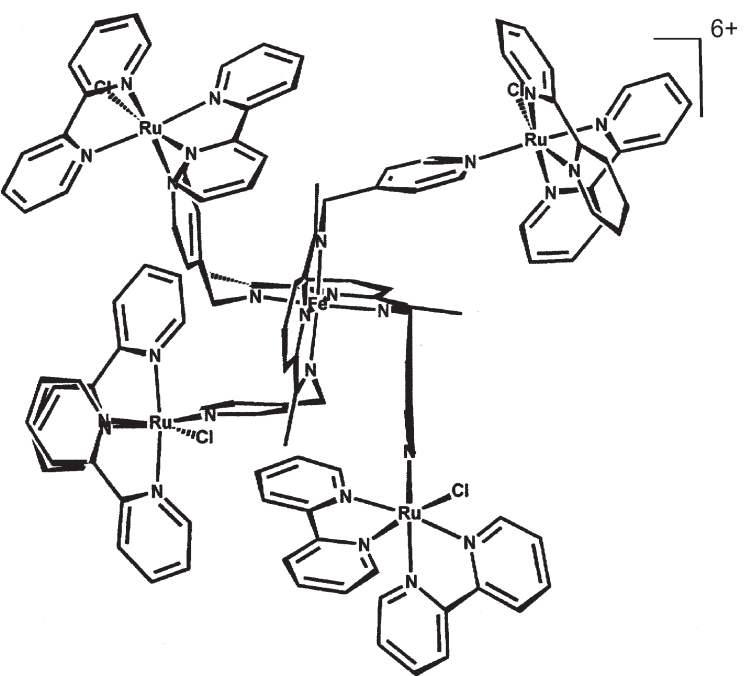

Figure 7. $\mathrm{MM}^{+}$structure of the supermolecule derived from bis(2,6diacetyl-4-methylpyridyliminepyridine)iron(II) incorporating four chlorobis(bipyridine)ruthenium(II) complexes.

An interesting multibinding complex has been obtained ${ }^{48}$ by attaching four aliphatic polyamine chains to a low spin, iron(II)-polyimine center, derived from 2,6diacetylpyridine, as shown in Figure 8.

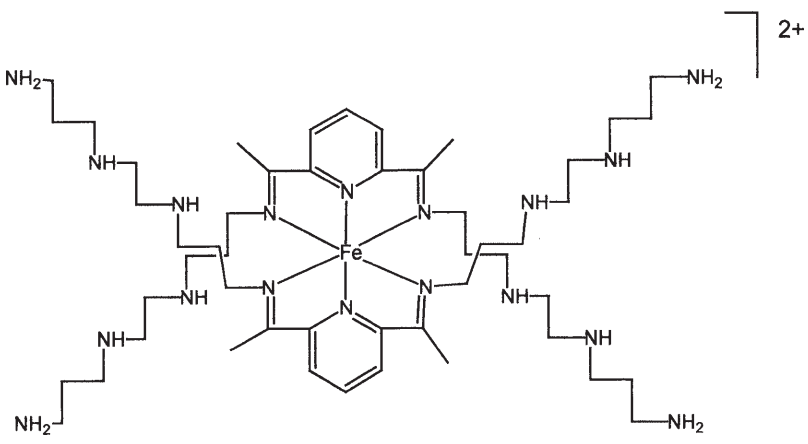

Figure 8. Structural representation of the bis(2,6-diacetylpyridyldiimine)iron(II) complex containing four aliphatic tetraamine substituents.

Molecular simulations for this complex corroborate the evidence from ${ }^{1} \mathrm{H}$ NMR spectroscopy of a symmetric structure, with the four polyamines displaying a tetrahedral arrangement around the metal center. The protonated polyamine complex interacts specifically with hexacyanoferrate(II) ions, generating an inclusion compound which has been characterized by means of vibrational and Mössbauer spectroscopy, and cyclic voltammetry. ${ }^{48}$ The proposed binding modes involve hydrogen bonding of four cyanide groups of the hexacyanoferrate(II) ion with the protonated amines, leaving two cyanide ligands for intermolecular interactions, as shown in Figure 9.

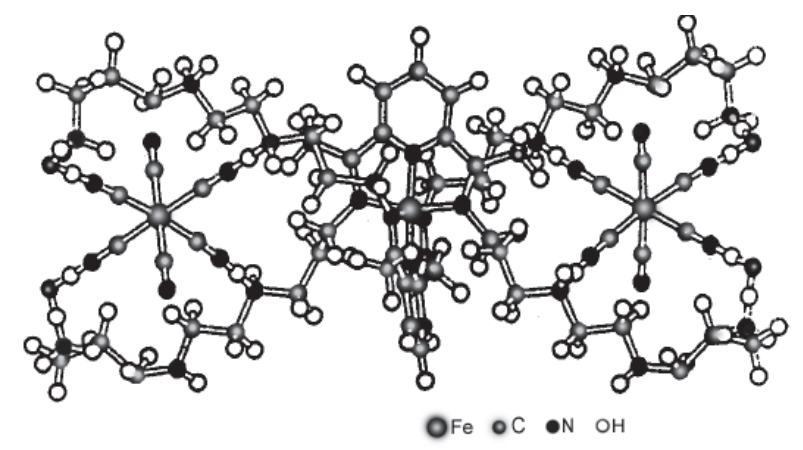

Figure 9. Illustration of the binding of the polyamine functionalized iron(II) complex ${ }^{38}$ with ferrocyanide anions (the atom labels are shown in Figure 8).

\section{Photoinduced Charge-Separation in Supramolecular Systems}

Polynuclear metal complexes containing phophysically active centers are particularly interesting from the point of view of photoinduced electron transfer and energy transfer processes. ${ }^{49-54}$ The presence of a metal complex attached to the photoactive center via a bridging ligand provides additional pathways for the deactivation 
of the excited states, and in some cases can promote effective charge-separation, giving rise to molecular dyad and triad devices. In these systems, the geometry, intermetallic separation distance, and electronic properties of the bridging ligands are relevant factors to be considered, in addition to the photochemical and photophysical characteristics of the metal ions.

Recently dyads and triads based on the photoactive, multibridging tris(bipyrazine)ruthenium(II) complex directly bound to transition metal complexes, have been generated $^{55}$ by following the coordination chemistry approach previously employed in the design of symmetric heptanuclear supermolecules, from $\left[\mathrm{Ru}(\mathrm{bpz})_{3}\right]^{2+}(\mathrm{bpz}=$ bipyrazine). ${ }^{56-58}$ Such new systems contain a tris(bipyrazine) ruthenium(II) ion attached to bis(bipyridine) chlororuthenium(II)/(III) or pentacyanoferrate(II)/(III) complexes via a bipyrazine bridging ligand, e.g., $\left[\mathrm{Ru}(\mathrm{bpz})_{3} \mathrm{Ru}(\mathrm{bipy})_{2} \mathrm{Cl}\right]^{3+/ 4+}$ or $\left[\mathrm{Ru}(\mathrm{bpz})_{3} \mathrm{Fe}(\mathrm{CN})_{5}\right]^{-10}$, as shown in Figure 10(A,B) (bipy = 2,2'-bipyridine). By attaching both complexes to the $\left[\mathrm{Ru}(\mathrm{bpz})_{3}\right]^{2+}$ center, the triad system $\left[(\mathrm{CN})_{5} \mathrm{Fe}^{\mathrm{III}}(\mathrm{bpz})_{2} \mathrm{Ru}^{\mathrm{II}}(\mathrm{bpz}) \mathrm{Ru}^{\mathrm{II}}(\mathrm{bipy})_{2} \mathrm{Cl}\right]^{+}$ (Figure 10C) has been obtained, after suitable oxidation of the iron(II) sites.

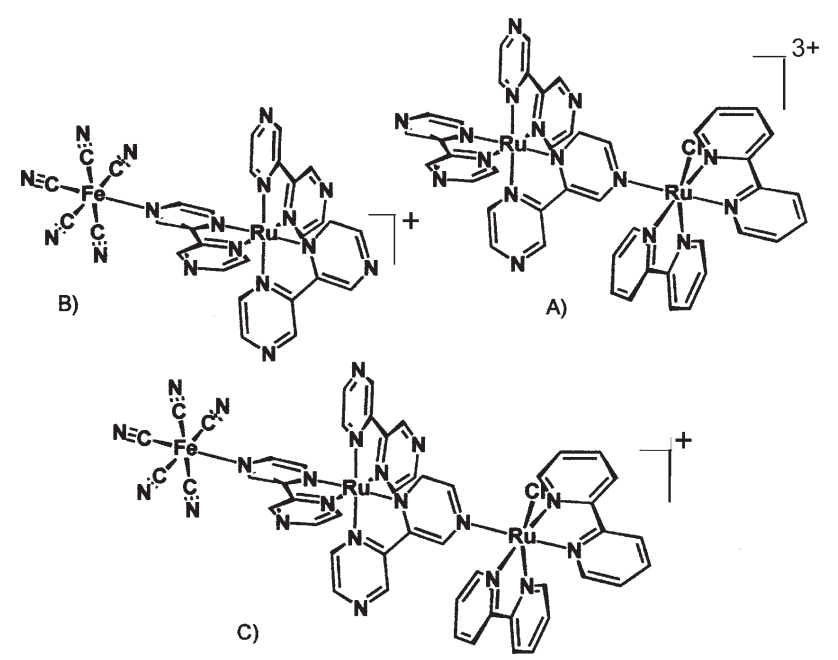

Figure 10. Structural representations of $(\mathrm{A}, \mathrm{B})$ diads and $(\mathrm{C})$ triad systems.

The electronic spectrum of the bimetallic complex in the visible region exhibits two strong, composite bands at 575 and $440 \mathrm{~nm}$. According to the calculations, the electronic band at $575 \mathrm{~nm}$ arises from the excitation from MO 155 (HOMO), mainly localized on the $\left[\mathrm{Ru}^{\mathrm{II}}(\mathrm{bipy})_{2} \mathrm{Cl}\right]^{+}$ moiety (71\%), to MO 156 (LUMO), mainly localized on the bridging bpz ligand (61\%); thus corresponding to a $\mathrm{Ru}_{\mathrm{p}}{ }_{\mathrm{II}} \rightarrow \mathrm{bpz}$ (bridge) charge-transfer transition. Another related transition, from MO 155 to MO 159 (the last one exhibiting $82 \%$ bpz bridge character), is theoretically expected at $487 \mathrm{~nm}$. It is however much less intense, being masked by the strong band at $575 \mathrm{~nm}$. The second characteristic band at $440 \mathrm{~nm}$ corresponds to the MO 152 $\rightarrow$ MO 157 transition centered on the $\left[\mathrm{Ru}^{\mathrm{II}}(\mathrm{bpz})_{3}\right]^{2+}$ chromophore. It is interesting to note that MO 152 involves $65 \% \mathrm{Ru}_{\mathrm{c}}{ }^{\mathrm{II}}+29 \%$ non-bridging bpz character. There is only little contribution of the bridging bpz ligand (5.8\%) to this level. Surprisingly, MO 157 exhibits $71 \%$ non-bridging bpz character, as compared with $16 \%$ for the bridging bpz one. Therefore, the absorption band at $440 \mathrm{~nm}$ involves preferential excitation of the $\mathrm{Ru}_{\mathrm{c}}{ }^{\mathrm{II}} \mathrm{d}_{\pi}$ electrons to the nonbridging bpz $\pi^{*}$ levels, rather than to the bridging bpz ones. The high energy transition as a shoulder at $410 \mathrm{~nm}$, corresponds to the MO $149 \rightarrow$ MO 156 excitation, where the first $\mathrm{MO}$ has $57 \% \mathrm{Ru}^{\mathrm{II}}{ }_{\mathrm{c}}$ character and the second one, $61 \%$ bridging bpz character. These results indicate that in the $\left[\mathrm{Ru}^{\mathrm{II}}(\mathrm{bpz})_{3}\right]^{2+}$ moiety, the excitation to the bridging bpz $\pi^{*}$ levels involves higher energies, as compared with the excitation to the corresponding non-bridging ligands.

At room temperature, the bimetallic complex exhibits only a weak asymmetric emission band at $608 \mathrm{~nm}$, associated with the $\left[\mathrm{Ru}(\mathrm{bpz})_{3}\right]^{2+}$ center, indicating substantial quenching from the $\left[\mathrm{Ru}\left(\text { bipy }{ }_{2} \mathrm{Cl}\right]^{+}\right.$moiety. The measured lifetime is $0.558 \mu \mathrm{s}$. The lack of emission from the $\left[\mathrm{Ru}(\text { bipy })_{2} \mathrm{Cl}(\mathrm{bpz})\right]^{+}$moiety is consistent with the fact that $\left[\mathrm{Ru}(\text { bipy })_{2} \mathrm{Cl}(\mathrm{pz})\right]^{2+}$ and related $\left[\mathrm{Ru}(\text { bipy })_{2} \mathrm{XY}\right]$ species are not good emitters at room temperature. ${ }^{59}$ This type of behavior has been ascribed to efficient mechanisms of deactivation of the ${ }^{3}$ MLCT excited state, associated with the existence of low energy ligand field states. ${ }^{49,60}$

The excitation process corresponds to:

$$
\begin{aligned}
{\left[(\mathrm{bpz})_{2} \mathrm{Ru}^{\mathrm{II}}(\mathrm{bpz}) \mathrm{Ru}^{\mathrm{II}}(\mathrm{bipy})_{2} \mathrm{Cl}\right]^{3+}+\mathrm{h} v \rightarrow } & \\
& {\left[(\mathrm{bpz})(\mathrm{bpz}) \mathrm{Ru}^{\mathrm{II}}(\mathrm{bpz}) \mathrm{Ru}^{\mathrm{II}}(\mathrm{bipy})_{2} \mathrm{Cl}\right]^{3+} }
\end{aligned}
$$

In this system, electron transfer in the excited bimetallic complex is expected to predominate over energy transfer. The electron transfer mechanism seems to be reflected in the contrasting emission lifetimes observed at room temperature $(0.558 \mu \mathrm{s})$ and at $77 \mathrm{~K}(9.4 \mu \mathrm{s})$. In general, electron transfer is less effective in solid glassy solvents at $77 \mathrm{~K}$, because of the outer-sphere reorganization requirements involved, ${ }^{61-65}$ thus increasing the luminescence lifetimes. Time resolved, differential absorption spectrum of the transient species shows a transient absorption signal around $430 \mathrm{~nm}$, reflecting the bleaching of the MLCT band in the starting $\left[\mathrm{Ru}(\mathrm{bpz})_{3}\right]^{2+}$ chromophore, while the rise of the absorption bands at 380 and $750 \mathrm{~nm}$ is consistent with the formation of the bpz radical species, as expected for the excited bimetallic complex, [(bpz)(bpz) $\left.\mathrm{Ru}^{\mathrm{III}}(\mathrm{bpz}) \mathrm{Ru}^{\mathrm{II}}(\mathrm{bipy})_{2} \mathrm{Cl}\right]^{3+*}$. 
An interesting point is the observed bleaching of the absorption around $600 \mathrm{~nm}$. This absorption coincides with the MLCT bands in the $\left[\mathrm{Ru}^{\mathrm{II}}(\text { bipy })_{2}(\mathrm{bpz}) \mathrm{Cl}\right]^{+}$moiety, and the observed changes can only be interpreted in terms of the occurrence of an intramolecular electron transfer process, generating the $\left[(\mathrm{bpz})\left(\mathrm{bpz}^{-}\right) \mathrm{Ru}^{\mathrm{II}}(\mathrm{bpz}) \mathrm{Ru}^{\mathrm{III}}(\mathrm{bipy})_{2} \mathrm{Cl}\right]^{3+}$ species, in parallel with the radiative and non-radiative decay processes, e.g.:

\section{$\left[(\mathrm{bpz})\left(\mathrm{bpz}-\mathrm{Ru}^{\mathrm{III}}(\mathrm{bpz}) \mathrm{Ru}^{\mathrm{II}}(\mathrm{bipy})_{2} \mathrm{Cl}\right]^{3+*} \rightarrow\right.$ $\left[(\mathrm{bpz})(\mathrm{bpz}) \mathrm{Ru}^{\mathrm{II}}(\mathrm{bpz}) \mathrm{Ru}^{\mathrm{III}}(\mathrm{bipy})_{2} \mathrm{Cl}\right]^{3+}$}

The decay of the $\left[(\mathrm{bpz})(\mathrm{bpz}) \mathrm{Ru}^{\mathrm{II}}(\mathrm{bpz}) \mathrm{Ru}^{\mathrm{III}}(\mathrm{bipy})_{2} \mathrm{Cl}\right]^{3+}$ transient species has been measured by means of flashphotolysis, proceeding according to a first order process with $\mathrm{k}=1.3 \times 10^{6} \mathrm{~s}^{-1}$, regenerating the starting $\left[(\mathrm{bpz})_{2} \mathrm{Ru}{ }^{\mathrm{II}}(\mathrm{bpz}) \mathrm{Ru}{ }^{\mathrm{II}}(\mathrm{bipy})_{2} \mathrm{Cl}\right]^{3+}$ complex.

\section{$\left[(\mathrm{bpz})\left(\mathrm{bpz}-\mathrm{Ru}^{\mathrm{II}}(\mathrm{bpz}) \mathrm{Ru}^{\mathrm{III}}(\mathrm{bipy})_{2} \mathrm{Cl}\right]^{3+} \rightarrow\right.$ $\left[(\mathrm{bpz})_{2} \mathrm{Ru}^{\mathrm{II}}(\mathrm{bpz}) \mathrm{Ru}^{\mathrm{III}}(\text { bipy })_{2} \mathrm{Cl}\right]^{3+}$}

The precursor trinuclear complex $\left[(\mathrm{CN})_{5} \mathrm{Fe}^{\mathrm{II}}(\mathrm{bpz})\right.$ $\mathrm{Ru}^{\mathrm{II}}(\mathrm{bpz})_{2} \mathrm{Ru}^{\mathrm{II}}(\text { bipy })_{2} \mathrm{Cl}^{+}$displays the characteristic MLCT bands in the $\left[\mathrm{Ru}(\mathrm{bpz})_{3}\right]^{2+},\left[\mathrm{Ru}(\mathrm{bipy})_{2}(\mathrm{bpz}) \mathrm{Cl}\right]^{+}$and $\left[\mathrm{Fe}(\mathrm{CN})_{5}(\mathrm{bpz})\right]^{3-}$ moieties at 440, 600 and $700 \mathrm{~nm}$, respectively. The three distinct moieties exhibit rather contrasting $\mathrm{E}^{\circ}$ values, i.e. 2.08, 1.14 and $0.70 \mathrm{~V}$, respectively. In this way, one can carry out a selective oxidation of the $\left[\mathrm{Fe}(\mathrm{CN})_{5}(\mathrm{bpz})\right]^{3-}$ group. This results in the decay of the absorption band at $700 \mathrm{~nm}$, so that the absorption spectrum of the mixed valence triad $\left[(\mathrm{CN})_{5} \mathrm{Fe}^{\mathrm{III}}(\mathrm{bpz}) \mathrm{Ru}^{\mathrm{II}}(\mathrm{bpz})_{2} \mathrm{Ru}^{\mathrm{II}} \text { (bipy) }{ }_{2} \mathrm{Cl}\right]^{-}$becomes very similar to that for the bimetallic $\left[\mathrm{Ru}^{\mathrm{II}}(\mathrm{bpz})_{3} \mathrm{Ru}^{\mathrm{II}}(\mathrm{bipy})_{2} \mathrm{Cl}\right]^{+}$ complex.

Such mixed valence triad does not exhibit detectable luminescence properties. However, rather interesting time resolved, differential absorption profiles have been obtained from flash photolysis experiments. Initially, in a nanosecond time scale, there is a bleaching of the absorption at $440 \mathrm{~nm}$, associated with the $\left[\mathrm{Ru}^{\mathrm{II}}(\mathrm{bpz})_{3}\right]^{2+}$ chromophore in the trinuclear complex, generating the $\left[(\mathrm{CN})_{5} \mathrm{Fe}^{\mathrm{III}}(\mathrm{bpz}) \mathrm{Ru}^{\mathrm{III}}\left(\mathrm{bpz}^{-}\right)(\mathrm{bpz}) \mathrm{Ru}^{\mathrm{II}}(\mathrm{bipy})_{2} \mathrm{Cl}\right]^{-*}$ excited state.

$$
\begin{aligned}
& {\left[(\mathrm{CN})_{5} \mathrm{Fe}^{\mathrm{III}}(\mathrm{bpz}) \mathrm{Ru}^{\mathrm{II}}(\mathrm{bpz})_{2} \mathrm{Ru}^{\mathrm{II}}(\mathrm{bipy})_{2} \mathrm{Cl}\right]^{-}+\mathrm{h} v \rightarrow} \\
& \quad\left[(\mathrm{CN})_{5} \mathrm{Fe}^{\mathrm{III}}(\mathrm{bpz}) \mathrm{Ru}^{\mathrm{III}}(\mathrm{bpz})(\mathrm{bpz}) \mathrm{Ru}^{\mathrm{II}}(\mathrm{bipy})_{2} \mathrm{Cl}\right]^{-*}
\end{aligned}
$$

The excited state decays according to a first order process, with $\mathrm{k}=7.4 \times 10^{7} \mathrm{~s}^{-1}$, regenerating the absorption band at $440 \mathrm{~nm}$. This process is accompanied by a partial bleaching of the absorption band at $600 \mathrm{~nm}$ associated with the $\left[\mathrm{Ru}(\text { bipy })_{2} \mathrm{Cl}\right]^{+}$chromophore, masking the rise of the absorption band of $\left[\mathrm{Fe}^{\mathrm{II}}(\mathrm{CN})_{5}(\mathrm{bpz})\right]^{3-}$ at $700 \mathrm{~nm}$, thus reflecting a sequence of steps which lead to long distance charge-separation, in the inverted mixed valence complex $\left[(\mathrm{CN})_{5} \mathrm{Fe}^{\mathrm{II}}(\mathrm{bpz}) \mathrm{Ru}^{\mathrm{II}}(\mathrm{bpz})_{2} \mathrm{Ru}^{\mathrm{III}}(\mathrm{bipy})_{2} \mathrm{Cl}\right]^{-}$.

$$
\begin{aligned}
& {\left[(\mathrm{CN})_{5} \mathrm{Fe}^{\mathrm{III}}(\mathrm{bpz}) \mathrm{Ru}^{\mathrm{III}}(\mathrm{bpz})(\mathrm{bpz}) \mathrm{Ru}^{\mathrm{II}}(\mathrm{bipy})_{2} \mathrm{Cl}\right]^{-*} \rightarrow} \\
& {\left[(\mathrm{CN})_{5} \mathrm{Fe}^{\mathrm{II}}(\mathrm{bpz}) \mathrm{Ru}^{\mathrm{II}}(\mathrm{bpz})_{2} \mathrm{Ru}^{\mathrm{III}}(\mathrm{bipy})_{2} \mathrm{Cl}\right]^{-}}
\end{aligned}
$$

The regeneration of the starting complex via chargerecombination is relatively slow, proceeding with a firstorder rate constant $\mathrm{k}=1.7 \times 10^{6} \mathrm{~s}^{-1}$

$$
\begin{aligned}
& {\left[(\mathrm{CN})_{5} \mathrm{Fe}^{\mathrm{II}}(\mathrm{bpz}) \mathrm{Ru}^{\mathrm{II}}(\mathrm{bpz})_{2} \mathrm{Ru}^{\mathrm{III}}(\mathrm{bipy})_{2} \mathrm{Cl}\right]^{-} \rightarrow} \\
& \quad\left[(\mathrm{CN})_{5} \mathrm{Fe}^{\mathrm{III}}(\mathrm{bpz}) \mathrm{Ru}^{\mathrm{II}}(\mathrm{bpz})_{2} \mathrm{Ru}^{\mathrm{II}}(\mathrm{bipy})_{2} \mathrm{Cl}\right]^{-}
\end{aligned}
$$

\section{Vectorial Energy Transfer and Antenna Effect}

One of the most important features responsible for the great efficiency of photosynthesis is the energy transfer process from the neighboring chromophores to the special pair, through the so called antenna effect. ${ }^{66-77}$ Because of their key role, energy transfer processes have been extensively studied for a number of systems. For instance, Lehn and co-workers. ${ }^{78}$ have shown that the luminescence from $\mathrm{Eu}^{2+}$ ion is enhanced by energy transfer from the criptate ligand containing three 2,2'-bipyridine subunits, especially when excited in the intraligand $\mathrm{p} \pi \rightarrow \mathrm{p} \pi^{*}$ transition.

Recently, a new calix[4]arene receptor (Figure 11) modified with 8-hydroxyquinoline has been reported by our group. ${ }^{79}$ This species exhibits a characteristic emission band at $488 \mathrm{~nm}$ associated with the 8-oxyquinoline group, and has been designed to incorporate the luminescent $\mathrm{Eu}^{3+}$ and $\mathrm{Tb}^{3+}$ ions by coordination of the oxygen atoms of the quinoline and calixarene units. In the case of the $\mathrm{Eu}^{3+}$ complex, a less intense 8-oxyquinoline fluorescence emission is observed at $490 \mathrm{~nm}$, accompanied by a series of narrow bands associated with the lanthanide ${ }^{5} \mathrm{D}_{0,1}$ to ${ }^{7} \mathrm{~F}$ transitions. The strongest europium ion emission is observed at $619 \mathrm{~nm}$, corresponding to the electric-dipole allowed ${ }^{5} \mathrm{D}_{0} \rightarrow{ }^{7} \mathrm{~F}_{2}$ hypersensitive transition. The excitation profile for the 8-oxyquinoline emission in the corresponding $\mathrm{Eu}^{3+}$ complex practically coincides with its absorption bands. In the phosphorescence mode, only the emission of the europium ion has been observed, while the excitation profiles are consistent with the energy transfer from the calixarene ring, rather than from the 8oxyquinoline one. According to the electronic spectra, the ${ }^{1} \pi \pi$ and ${ }^{3} \pi \pi$ levels of calixarene are higher in energy than those of the 8-oxyquinoline group. The efficient calixarene 
singlet-triplet conversion by the heavy metal effect promotes energy transfer to the ${ }^{5} \mathrm{D}_{0}$ level of $\mathrm{Eu}^{3+}$, thus explaining the observed antenna effect. Presumably, since the ${ }^{1} \pi \pi^{*}$ of 8 -oxyquinoline occurs at $490 \mathrm{~nm}$, the ${ }^{3} \pi \pi^{*}$ level is lower than the ${ }^{5} \mathrm{D}_{0}$ level of $\mathrm{Eu}^{3+}$.

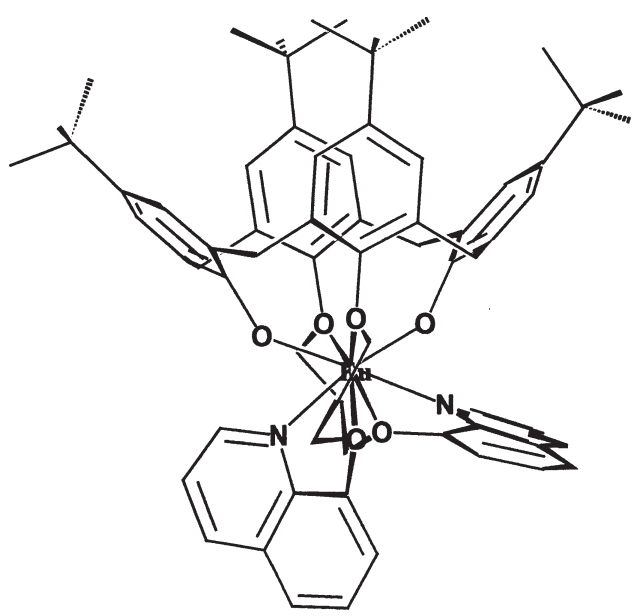

Figure 11. Structural representation of the Eu(III)-\{calix[4]arenebis(8-oxyquinoline)\} complex

Similar Eu(III) complexes containing three $\beta$-diketone and one 2,2'-bipyridine ligands have been reported by Gameiro et al. ${ }^{80-82}$ Those complexes exhibit the characteristic $\mathrm{Eu}(\mathrm{III})$ emission, under UV irradiation, promoted by efficient antenna effect, as in the case of the calix[4]arene complex. However, in the case of the 4,4,4trifluoro-1-fenil-1,3-butadione (btfa) complex, i.e. $\left[\mathrm{Eu}(\mathrm{btfa})_{3}(\mathrm{bipy})\right]$, the lanthanide emission is supressed, presumably by photodecomposition reactions. This property has been exploited for the design of rather promissing molecular dosimeters, for UV exposure.

The occurrence of vectorial energy transfer ${ }^{68,75,83}$ has also been reported for a zinc porphyrin species modified with four tris-(4,4'-dimethyl-2,2'-bipyridine)ruthenium(II) complexes covalently bound at the meso- positions, ${ }^{84}$ $\left[\text { ZnTBipyP }\left\{\mathrm{Ru}(\text { dmbipy })_{2}\right\}_{4}\right]^{8+}$ (Figure 12).

Such species exhibited a characteristic metalloporphyrin spectrum, with absorption bands at 437 (Soret), 570 and $615 \mathrm{~nm}$; in addition to the ruthenium complex bands at $295\left(\pi \rightarrow \pi^{*}\right)$ and $490 \mathrm{~nm}$ (MLCT). It is interesting to note that the Soret band is broadened and less intense than in conventional or analogous supermolecular porphyrins. ${ }^{76,77}$ This behavior is similar to that previously ascribed $^{85}$ to the coupling between the transition moment vectors of the Soret and $\mathrm{Ru}^{\mathrm{II}}(\mathrm{d} \pi) \rightarrow$ bipy $\left(\mathrm{p} \pi^{*}\right)$ transitions. The coupling is favored when the difference between the transition energies tends to zero and the oscillator strengths are high. In the case of $\left[\mathrm{ZnTBipyP}\left\{\mathrm{Ru}(\mathrm{dmbipy})_{2}\right\}_{4}\right]^{8+}$, the

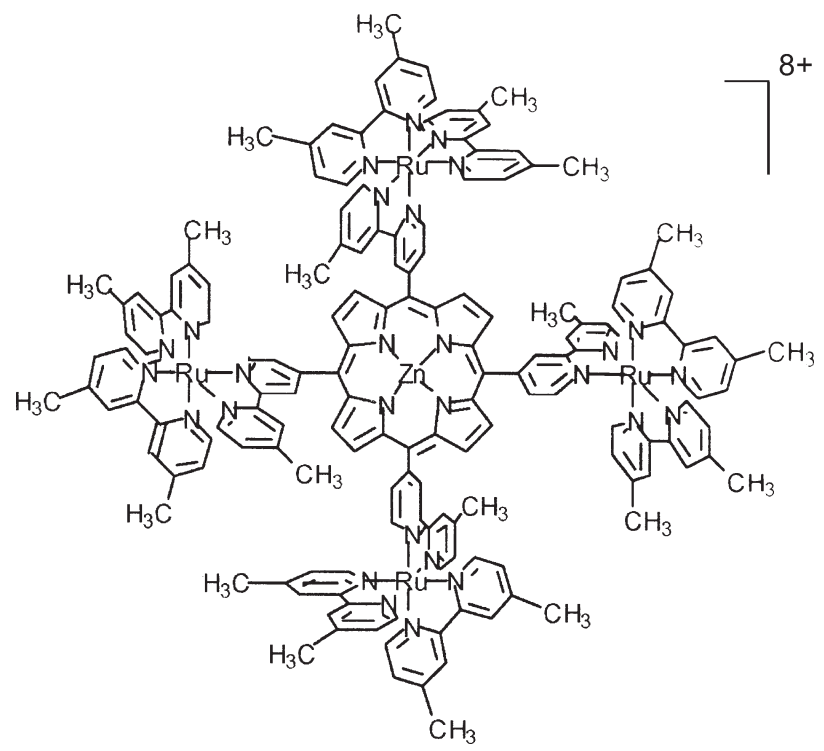

Figure 12. Structural representation of the complex $\left[\text { ZnTBipyP }\left\{\operatorname{Ru}(\text { dmbipy })_{2}\right\}_{4}\right]^{8+}$.

porphyrin transitions are sensitive to coordination effects, while the ruthenium complex transitions are virtually insensitive. This characteristic has been used to tune the electronic coupling between the central and peripheral subunits, by shifting the porphyrin energy levels.

The structure of $\left.\left[\text { ZnTBipyP }\{\text { Ru(dmbipy })_{2}\right\}_{4}\right]^{8+}$ molecule has been especially designed for efficient vectorial energy transfer from the peripheral ruthenium complexes to the porphyrin moiety. In this system, the excited triplet MLCT states of the ruthenium complexes are energetically close to the lowest singlet excited state (S1) of the zinc porphyrin. It is known that the excited electron in the MLCT state of ruthenium bipyridine complexes is localized in the bipyridine ring with the lowest energy $\pi^{*}$ state. On the other hand, the $\pi^{*}$ energy level of the 4,4'-dimethyl-2,2'-bipyridine ligands in the $\left[\mathrm{Ru}^{\mathrm{II}}\left(4,4^{\prime}-\text { dmbipy }\right)_{3}\right]^{2+}$ complexes is higher than of ruthenium complexes with non substituted bipyridine ligands, ${ }^{22,23}$ such that their emission bands occur at 633 $\mathrm{nm}$ and $613 \mathrm{~nm}$, respectively. In the supramolecular complex all the bipyridine rings of the peripheral complexes have a methyl substituent, except for the bridging ring that is bound to the aromatic porphyrin ring. Thus, the excited electron should be preferentially localized on the bridging pyridyl ring, facilitating the vectorial energy transfer processes from the ruthenium complexes to the porphyrin ring.

When excited at $500 \mathrm{~nm}$ (ruthenium complex MLCT transition) $\left[\mathrm{ZnTBipyP}\left\{\mathrm{Ru}(\mathrm{dmbipy})_{2}\right\}_{4}\right]^{8+}$ exhibits predominantly ruthenium complex emission pattern, but showing significant contribution of the zinc porphyrin 
emission. On the other hand, the spectrum obtained after excitation at the Q band at $570 \mathrm{~nm}$ is dominated by the $\mathrm{S}_{1}$ zinc porphyrin emission; however, a significant contribution from $\left[\mathrm{Ru}(\mathrm{dmbipy})_{3}\right]$ complex emission can also be found. The observations show that the $\mathrm{S} 1$ and MLCT $\mathrm{M}_{1}$ states are rather close in energy, supporting the hypothesis of thermally equilibrated excited MLCT $_{1}$ and porphyrin singlet states. Selective perturbation of the energies of those excited states was carried out by coordinating an imidazole ligand to the zinc porphyrin center. As a result, the zinc porphyrin bands shifted from 450 (Soret), 570 and $614 \mathrm{~nm}$ to 457,575 and $625 \mathrm{~nm}$. Because of the lowering the energy of the corresponding excited state, the emission spectra of that supermolecule exhibit essentially a zinc porphyrin like pattern, when excited at both wavelengths 500 and $570 \mathrm{~nm}$. Therefore, even such small energy decrease (290 $\mathrm{cm}^{-1}$ ) in the $S_{1}$ state, has been enough to drive the energy transfer from the excited peripheral ruthenium complexes to the central zinc porphyrin moiety. This antenna effect has been confirmed by the excitation spectrum, which reproduced the zinc porphyrin and ruthenium complexes absorption bands.

\section{Singlet Oxygen Generation and DNA Photocleavage}

An important application of photosensitizing compounds is based on their ability to promote photoinduced damage to biological molecules including lipids, proteins and DNA, allowing the eradication of early localized tumors by the use of light. This type of medical treatment is known as photodynamic therapy (PDT). The sensitizing properties of various molecules, such as methylene blue, transition metal polypyridines and porphyrins have been extensively investigated in the last decades, aiming the development of efficient PDT drugs, imparting minima medical problems. ${ }^{86-97}$ It is well established that the activity of such drugs is closely related to their ability to interact with cellular membranes and macromolecules, such as double-stranded DNA. For this reason, the interaction between the photosensitizing agents and DNA represents a relevant issue for investigation.

Recent work from our laboratories has focused on the plasmid pBR322 and DNA interactions with a free-base tetraruthenated porphyrin species (TRP), revealing the occurrence of light induced single-strand breaks and 8oxo-7,8-dihydro-2'-deoxyguanosine formation in the presence of molecular oxygen ${ }^{86}$ The special sensitizer employed combines the remarkable redox and photochemical/photophysical properties of the porphyrins and ruthenium(II)-polypyridine compounds, in addition to their ability to strongly bind DNA via intercalation and outside association. ${ }^{87-91}$ Analogously to its molecular components, the TRP species exhibits a potential usefulness in photodynamic therapy (PDT) applications. ${ }^{92,93}$ From the supramolecular point of view, the peripheral ruthenium-polypyridine groups interact with the porphyrin center, promoting energy and electron transfer processes, and enhancing the photodynamic properties of the molecule. ${ }^{71}$

Two types of mechanisms have been associated with the photosensitized reactions involving DNA. ${ }^{94}$ The so called type I mechanism involves direct electron transfer or hydrogen abstraction of the 2'-deoxyguanosine (dGuo) bases by the excited sensitizer, while type II proceeds via their reaction with singlet oxygen, $\mathrm{O}_{2}\left({ }^{1} \Delta_{\mathrm{g}}\right)$, yielding 8 oxo-2'-deoxyguanosine (8-oxodGuo) and 4-hydroxy-8oxo-4,8-dihydro-2'-deoxyguanosine. Recently, the photodynamic properties of TRP and its zinc metallated derivative, ZnTRP (Figure 4), have been evaluated ${ }^{95}$ in comparison with methylene blue and riboflavin, using 2'-deoxyguanosine as a model compound. ${ }^{96,97}$ Riboflavin is a characteristic type I photosensitizer, while methylene blue exhibits a type II behavior. The selectivity measured by the ratio of the amount of photoproducts generated by type II/type I mechanisms was 0.4 for riboflavin, and 2.3, 3.6 and 5.6 for TRP, methylene blue and ZnTRP, respectively, showing that $\mathrm{ZnTRP}$ is the most specific type II photosensitizer of the series.

The binding of ZnTRP to CT-DNA has been monitored from the corresponding DNA-induced changes on the UVVis absorption and luminescence spectra in aqueous solution. The addition of increasing amounts of DNA (in the range of 0 to $17.9 \mu \mathrm{mol} \mathrm{L}{ }^{-1}$ ) to the ZnTRP solution leads, initially, to a pronounced hypochromic effect on the Soret band at $426 \mathrm{~nm}$ (Figure 13). However, at higher concentrations of DNA the Soret band shifts to $438 \mathrm{~nm}$ and a systematic increase of the absorption is observed, evidencing a change in the interaction mode between those species. The binding constants for the low and high DNA concentration ranges, $\mathrm{K}_{1}=5.0 \times 10^{7}$ and $\mathrm{K}_{2}=1.0 \times 10^{5}$ mol L $\mathrm{L}^{-1}$, respectively, can be compared with those found ${ }^{86}$ for $\operatorname{TRP}\left(\mathrm{K}_{1}=2.5 \times 10^{4}\right.$ and $\left.\mathrm{K}_{2}=1.5 \times 10^{5} \mathrm{~mol} \mathrm{~L}^{-1}\right)$. A stronger electrostatic interaction of ZnTRP with the DNA chain in the low DNA concentration range (Figure 2) is evidenced with respect to the TRP analogue.

The luminescence spectrum of ZnTRP exhibits a strong emission band at $621 \mathrm{~nm}$ and a side band at $660 \mathrm{~nm}$ assigned to the $\mathrm{Q}_{0-0}$ and $\mathrm{Q}_{0-1}$ porphyrin transitions, respectively, as shown in Figure 14. In the low DNA concentration range, e.g. below $15 \mu \mathrm{mol} \mathrm{L}^{-1}$, the luminescence intensity at $621 \mathrm{~nm}$ decreases systematically to 


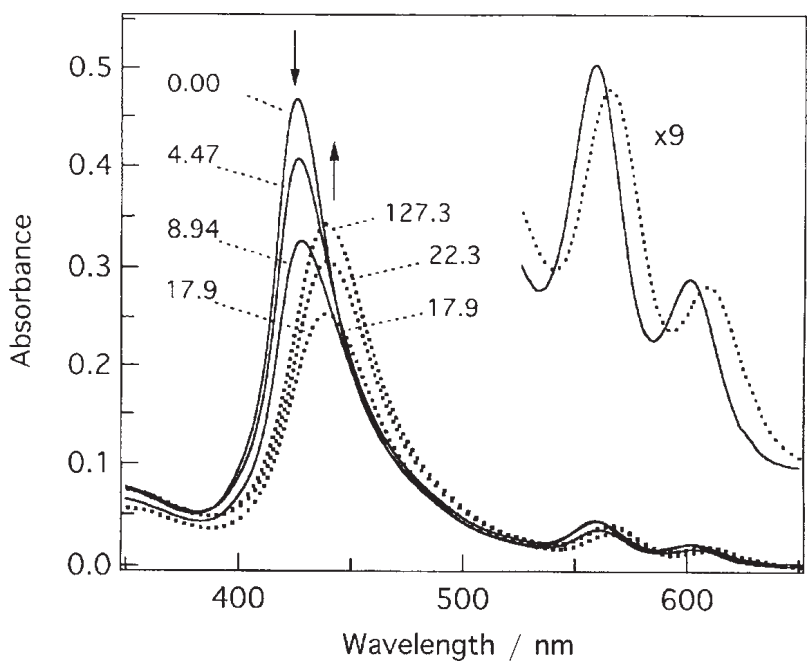

Figure 13. Spectrophotometric titration of a $1.3 \mu \mathrm{mol} \mathrm{L}^{-1}$ ZnTRP aqueous solution with CT-DNA (concentrations in $\mu \mathrm{mol} \mathrm{L}^{-1}$ ). Inset: expanded view of the $\mathrm{Q}$ bands at the initial and final conditions.

about $1 / 3$ of the initial value and the resulting spectral profile becomes very broad. This type of behavior differs from that previously reported for the TRP-DNA system, ${ }^{86}$ in which case, only a systematic increase in the luminescence has been detected.

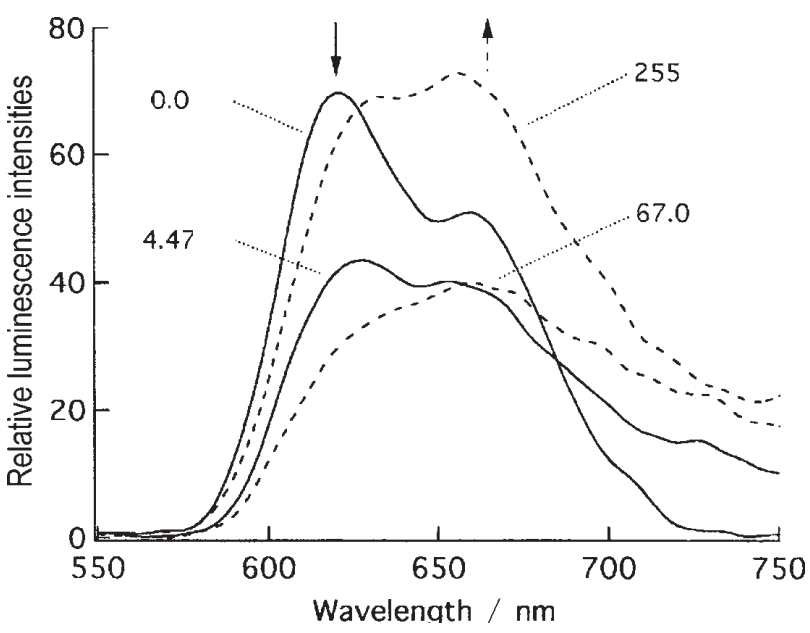

Figure 14. Fluorescence spectrum of ZnTRP as the concentration of CT-DNA is increase from 0 to 8.94 and from 8.94 to $255 \mu \mathrm{mol} \mathrm{L}^{-1}$.

Presumably, the presence of the metal ion can play an important role, by promoting strong electrostatic interactions of the phosphate residues with the cationic ZnTRP species, in addition to their possible coordination to the $\mathrm{Zn}$ center. This would explain the observed increase in the electrostatic binding constant.

In the high DNA concentration range (up to $255 \mu \mathrm{mol} \mathrm{L}^{-1}$ ), a systematic increase of the luminescence emission at $630 \mathrm{~nm}$ has been observed. This process is accompanied by an inversion in the spectral pattern, making the $660 \mathrm{~nm}$ band more intense. The luminescence spectra are coherent with the observed changes in the UVVis spectra as a function of the DNA concentration, confirming the occurrence of two distinct binding modes in the ZnTRP - DNA system. This type of behavior has also been reported for a number of systems ${ }^{89,91}$ and interpreted in terms of a switch from electrostatic to intercalation mode as the concentration of DNA increases.

2'-Deoxyguanosine (dGuo) is the critical DNA target component in both type I and II photosensitization mechanisms, consisting in a good model compound for understanding the photoinduced oxidation of DNA. Type I mechanism is known to convert dGuo into oxazolone and imidazolone products through a mechanism that involves an electron transfer from the excited photosensitizer to DNA. Type II mechanism involves energy transfer from the excited sensitizer to dioxygen, yielding $\mathrm{O}_{2}\left({ }^{1} \Delta_{\mathrm{g}}\right)$ reactive species which convert dGuo into the oxidation products 8-oxodGuo and 4-hydroxy-8-oxo-4,8dihydro-2'-deoxyguanosine. ${ }^{96-98}$ From the quantification of the different oxidation products, $\mathrm{O}_{2}\left({ }^{1} \Delta_{\mathrm{g}}\right)$ species has been postulated as the reactive species in dGuo photooxidation mechanisms mediated by the tetraruthenated porphyrins. $^{96}$

Direct evidence of the formation of $\mathrm{O}_{2}\left({ }^{1} \Delta_{\mathrm{g}}\right)$ in photoexcitation of ZnTRP in air saturated acetonitrile solutions, has been obtained from its characteristic phosphorescence emission decay at $1270 \mathrm{~nm}^{98}$ (Figure 15). The calculated life time was $\tau=(8.0 \pm 0.1) \times 10^{-5} \mathrm{~s}$. The efficiency of ZnTRP as a photosensitizer in the photooxidation of DNA has been investigated by monitoring the formation of 8-oxodGuo residues as a function of time and ZnTRP concentration. The amount of 8-oxodGuo increases linearly with the concentration of ZnTRP, when the time of exposure and irradiation intensity were kept constant, as expected for a photooxidation process promoted by the porphyrin sensitizer. The amount of 8-oxodGuo residues formed as a function of the irradiation time follows a single exponential behavior, $(\mathrm{k}=$ $0.019 \pm 0.005 \mathrm{~min}^{-1}$ ) and the following scheme has been proposed:

$$
\begin{aligned}
& \mathrm{TRP}+\mathrm{h} v \rightarrow \mathrm{TRP}^{*} \\
& \mathrm{TRP}^{*}+\mathrm{O}_{2}\left({ }^{3} \Sigma_{\mathrm{g}}\right) \rightarrow \mathrm{TRP}+\mathrm{O}_{2}\left({ }^{1} \Delta_{\mathrm{g}}\right) \\
& \mathrm{O}_{2}\left({ }^{1} \Delta_{\mathrm{g}}\right)+\mathrm{DNA} \rightarrow \text {-oxodGuo }
\end{aligned}
$$

Photooxidation kinetics carried out using dGuo instead of CT-DNA have resulted in similar rate constant $\left(0.018 \mathrm{~min}^{-1}\right)$, confirming that deoxyguanosine is the preferential target for $\mathrm{O}_{2}\left({ }^{1} \Delta_{\mathrm{g}}\right)$. 


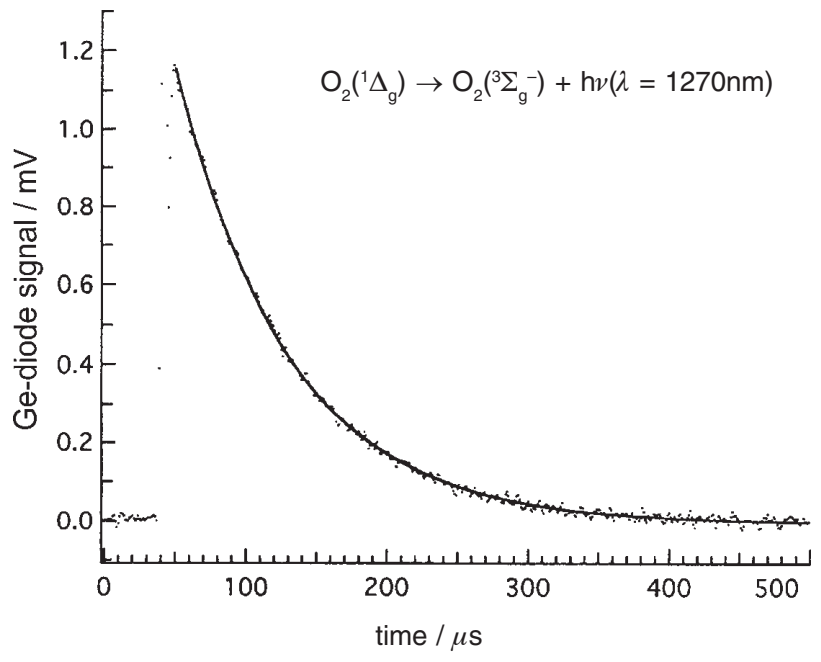

Figure 15. Phosphorescence decay of $\mathrm{O}_{2}\left({ }^{1} \Delta_{\mathrm{g}}\right)$ at $1270 \mathrm{~nm}$, at room temperature, after pulse excitation of $2 \mu \mathrm{mol} \mathrm{L}^{-1} \mathrm{ZnTRP}$ in normally aerated acetonitrile.

\section{Oxidative Catalysis and Cytochrome P-450 Activity}

Manganese and iron porphyrins have been extensively studied as models of cytochrome P-450 because they act as good oxygen atom transfer catalysts. ${ }^{99,100}$ The active species consist of high-valence metal-oxo porphyrins, which are very reactive and sensitive to substituent effects at the meso-aryl and $\beta$-pyrrol carbon atoms. The binding of selected metal complexes ${ }^{101-103}$ such as the trinuclear $\mu_{3}$-oxo-ruthenium acetate clusters ${ }^{24,104-110}$ to the periphery of the metalloporphyrin ring provides an interesting strategy ${ }^{111}$ to improve the activity of the porphyrin catalyst, as in the MnTCP species ${ }^{112}$ (Figure 16), as a consequence of their electron withdrawing/donor and/or electron transfer properties, or by acting as cofactors, or by creating new pathways for the oxidation of organic substrates.

The catalytic activity of the supramolecular MnTCP and of the porphyrin species MnTPyP has been compared in the epoxidation of cyclooctene by iodosylbenzene in acetonitrile. ${ }^{112}$ Both compounds seem to catalyze efficiently and selectively the epoxidation of this substrate. However, in the oxidation of cyclohexane, a less reactive substrate, the results have been remarkably different. MnTPyP leads to the formation of cyclohexanone (13\%) and cyclohexanol (27\%) in about 1:2 molar ratio, but MnTCP generates exclusively cyclohexanol (45\%) keeping the same total yield.

In this type of system, high-valent metal-oxo porphyrins such as $\mathrm{O}=\mathrm{Mn}^{\mathrm{V}} \mathrm{P}$ have been proposed as the active species. ${ }^{99,100}$ Such species are very reactive and can not be detected under the conditions employed for catalysis. Its existence has been evidenced by Groves and

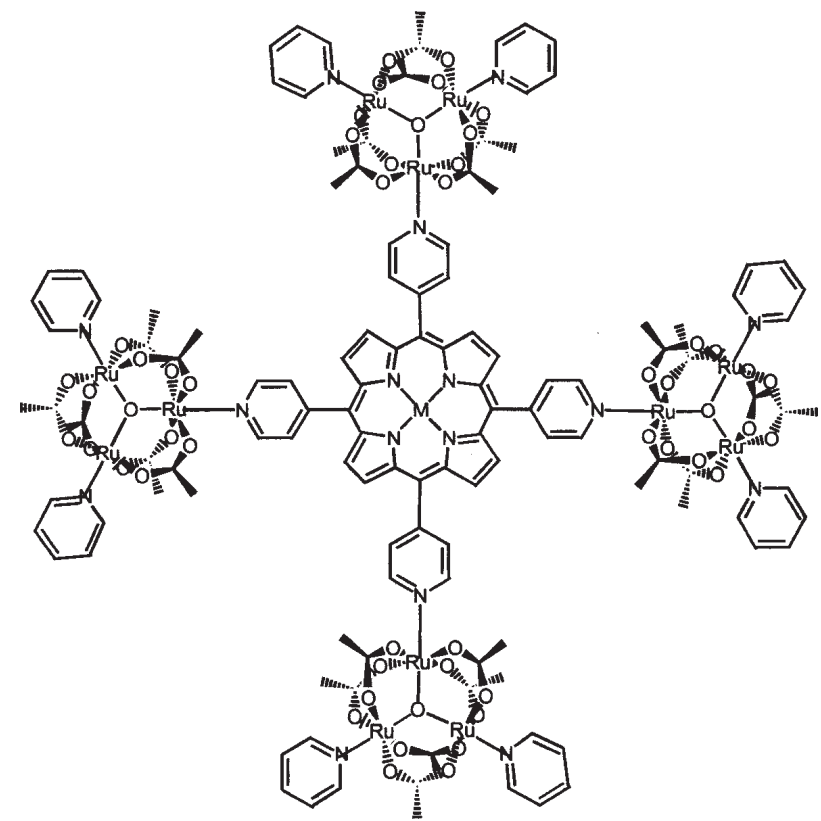

Figure 16. Structural representation of $\left[\mathrm{MnTPyP}\left\{\mathrm{Ru}_{3} \mathrm{O}\left(\mathrm{CH}_{3} \mathrm{COO}\right)_{6}\right.\right.$ (py) $\left.\}_{4}\right]^{5+}$, MnTCP.

$\mathrm{Jin}^{113}$ in a stopped-flow reaction of $\mathrm{Mn}^{\mathrm{II}} \mathrm{T}(4-\mathrm{MPyP})$ with chloroperoxybenzoic acid in aqueous solution. In this case, the formation of the $\mathrm{O}=\mathrm{Mn}^{\mathrm{V}} \mathrm{T}(4-\mathrm{MPyP})$ species was found to be complete after $30 \mathrm{~ms}$, and is followed by a slower first-order reaction which leads to the formation of the less reactive $\mathrm{O}=\mathrm{Mn}^{\mathrm{IV}} \mathrm{T}(4-\mathrm{MPyP})$ species. More recently, a stable $\mathrm{O}=\mathrm{Mn}^{\mathrm{V}} \mathrm{T}(2-\mathrm{MPyP})$ was characterized by ${ }^{1} \mathrm{H}-\mathrm{NMR}$ spectroscopy. ${ }^{114}$

The efficiency and high selectivity of MnTCP is consistent with the involvement of $\mathrm{O}=\mathrm{Mn}^{\mathrm{V}} \mathrm{TCP}$ as catalyst rather than $\mathrm{O}=\mathrm{Mn}^{\mathrm{IV}} \mathrm{TCP}$. In fact, the related $\mathrm{O}=\mathrm{Mn}^{\mathrm{IV}} \mathrm{T}(4-$ $\mathrm{MPyP})$ species has been reported to be much less reactive than $\mathrm{O}=\mathrm{Mn}^{\mathrm{V}} \mathrm{T}(4-\mathrm{MPyP})$ leading to reactions involving radical species, presumably responsible for the formation of cyclohexanone. Attempts to detect the $\mathrm{O}=\mathrm{Mn}^{\mathrm{V}} \mathrm{TCP}$ species have been carried out by rapidly mixing MnTCP and iodosylbenzene solutions using a suitable flow-cell device, and measuring the UV-Vis spectra with a diodearray spectrophotometer. The final spectrum, however, corresponds to the $\mathrm{O}=\mathrm{Mn}^{\mathrm{IV}} \mathrm{TCP}$ species, ${ }^{115,116}$ containing a mixture of $\mathrm{Ru}^{\text {III }} \mathrm{Ru}^{\mathrm{III}} \mathrm{Ru}^{\mathrm{IV}} / \mathrm{Ru}^{\mathrm{III}} \mathrm{Ru}^{\mathrm{III}} \mathrm{Ru}^{\mathrm{III}}$ redox states $\left(\mathrm{E}^{0}=\right.$ $1.17 \mathrm{~V})$. From this observation, the redox potential $\mathrm{O}=\mathrm{Mn}^{\mathrm{V}} \mathrm{TCP}$ species should be higher than $1.17 \mathrm{~V}$ and all peripheral clusters should be in the $\mathrm{Ru}^{\mathrm{IV}} \mathrm{Ru}^{\mathrm{III}} \mathrm{Ru}{ }^{\mathrm{III}}$ form.

\section{Electric Conductivity, Rectifying Effects and Photoaction Response of Supramolecular Films}

An interesting supramolecular species (here denoted $\mathrm{TRPz}=$ tetraruthenated porphyrazine) is constituted by 
the free-base (3,4-pyridyl)porphyrazine coordinated to four peripheral $\left[\mathrm{Ru}(\text { bipy })_{2} \mathrm{Cl}\right]^{+}$groups $^{71}$ (Figure 17). In this system, the pyridyl groups are fused to the macrocycle ring, in contrast with the related meso-tetra(4pyridyl)porphyrins, ${ }^{117} \mathrm{TPyP}$, allowing a strong electronic interaction between the central and peripheral complexes, as reflected in an efficient antenna effect .

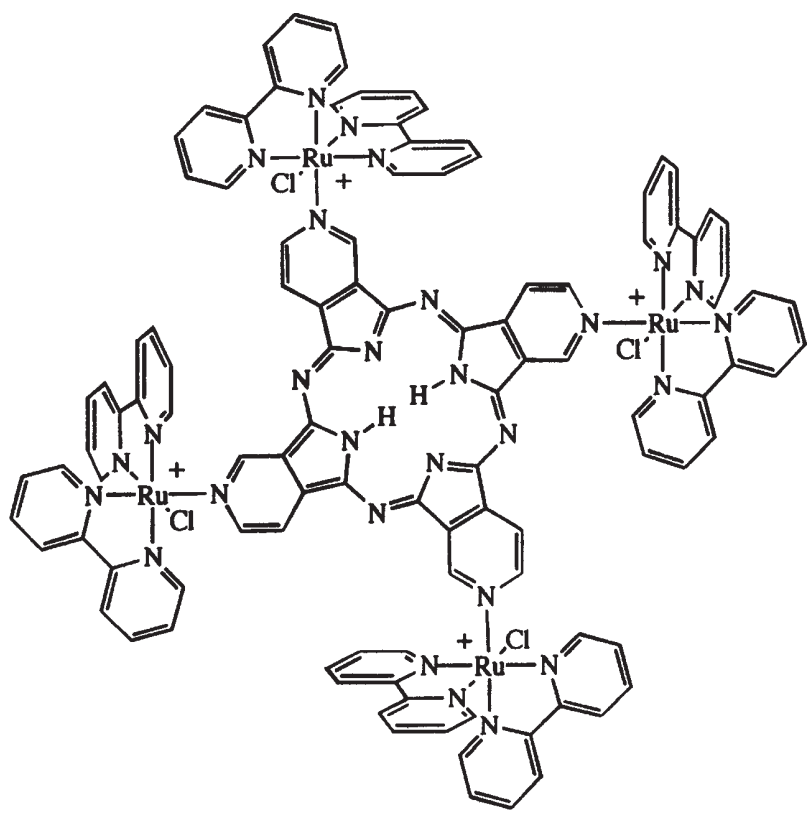

Figure 17. Structural representation of the $\mu$-\{(3,4-pyridyl) porphyrazine $\}$-tetrakis $\{$ bis-bipiridine(chloro)ruthenium(II) complex, TRPz.

A typical electronic spectrum of the TRPz species in ethanol can be seen in Figure 18. The deconvoluted spectrum based on bigaussian functions exhibits the porphyrazine bands at $380\left(\mathrm{~B}_{0-1}\right), 406\left(\mathrm{~B}_{0-0)}, 594\left(\mathrm{Q}_{\mathrm{y} 0-1}\right)\right.$, $638\left(\mathrm{Q}_{\mathrm{x} 0-1}\right), 677\left(\mathrm{Q}_{\mathrm{y} 0-0}\right)$ and $708 \mathrm{~nm}\left(\mathrm{Q}_{\mathrm{x} 0-0}\right)$. The remaining bands at 294, 344, 436 and $498 \mathrm{~nm}$ are attributed to the bipy $\left(\mathrm{p} \pi \rightarrow \mathrm{p} \pi^{*}\right)$ and $\mathrm{Ru}^{\mathrm{II}}(\mathrm{d} \pi) \rightarrow \operatorname{bipy}\left(\mathrm{p} \pi_{2}{ }^{*}\right), \mathrm{Ru}^{\mathrm{II}}$ $(\mathrm{d} \pi) \rightarrow \mathrm{py}\left(\mathrm{p} \pi^{*}\right)$, and $\mathrm{Ru}^{\mathrm{II}}(\mathrm{d} \pi) \rightarrow$ bipy $\left(\mathrm{p} \pi_{1}^{*}\right)$, MLCT transitions, respectively.

The emission spectrum of the TRPz species is characterized by the porphyrazine luminescence, at 720 $\mathrm{nm}$ (Figure 18), while the excitation profile practically coincides with the absorption spectra, reproducing even the MLCT band at $500 \mathrm{~nm}$, of the peripheral ruthenium complexes. Such coincidence corroborates the occurrence of efficient energy transfer processes from the ruthenium complexes to the porphyrazine center, in contrast to the related supramolecular tetrapyridyl derivatives.

Analogously to the supramolecular TPyP systems, the tetraruthenated porphyrazine species also form very homogeneous molecular films onto solid surfaces, by the

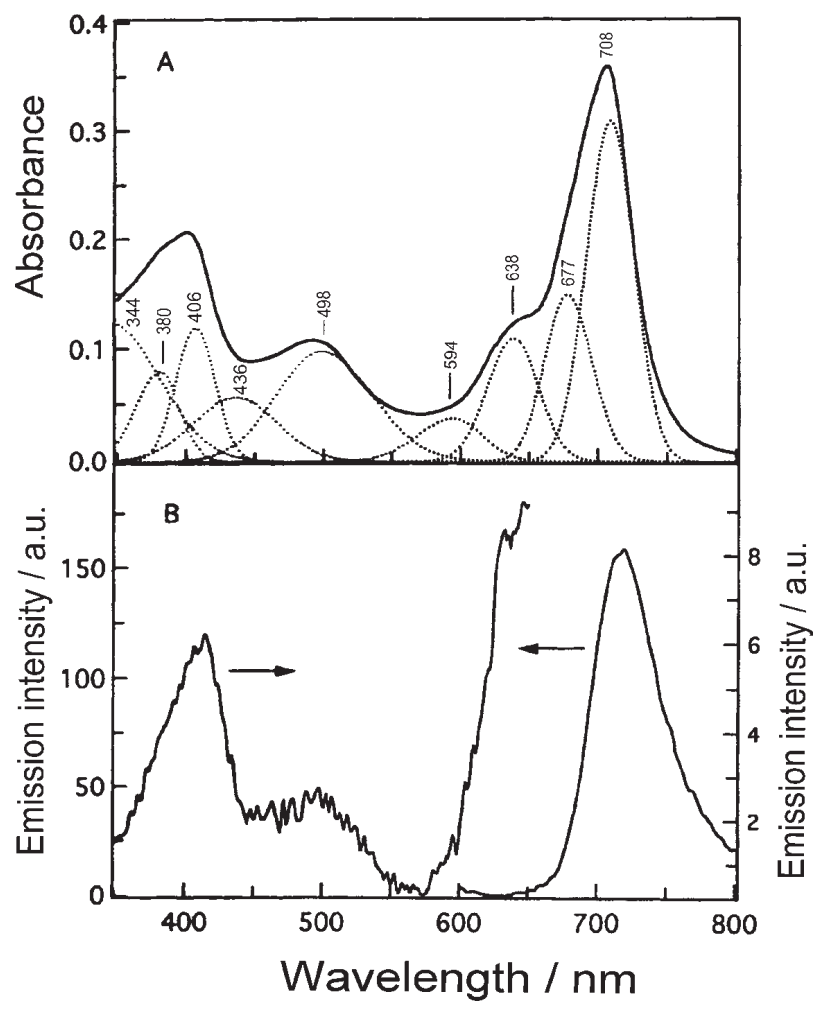

Figure 18. (A) Electronic spectrum (deconvoluted) of the TRPz complex (room temperature, ethanol solution, $2.6 \mu \mathrm{mol} \mathrm{L}^{-1}$ ) and the corresponding (B) emission spectrum recorded at $\lambda_{\text {ex }}=400 \mathrm{~nm}$, and excitation profile recorded at $\lambda_{\mathrm{em}}=725 \mathrm{~nm}$.

slow evaporation of the solvent (e.g. methanol). Such films are suitable for the preparation of modified electrodes, displaying versatile electrochemical and photoelectrochemical properties. Another strategy is provided by the controlled electrostatic/stacking assembly of cationic TRPz and suitable anionic species, such as the tetrasulfonatephthalocyaninatecopper(II) complex, CuTSPc, yielding the corresponding TRPz/CuTSPc double layered films ${ }^{66,118}$ as illustrated in Figure 19. Both films exhibit electron hopping conductivity at the onset of the film oxidation wave; however, a remarkable aspect of the stacked ion pair film is the occurrence of an additional, fast electron transfer mechanism. This finding was associated with electronic conduction through the films, arising from the formation of porphyrazine/ phthalocyanine columnar stacks with extended $\pi$ interaction.

The spectrum of a TRPz film on ITO is analogous to the solution spectrum exhibiting the Soret band at 390 and a broad Q band at $705 \mathrm{~nm}$, respectively; and the peripheral ruthenium complexes $\pi-\pi^{*}$ and charge transfer bands at 300 and $500 \mathrm{~nm}$. When a TRPz solution in dimethylsulfoxide is titrated with CuTSPc in the same solvent, the $\mathrm{Q}$ band at $710 \mathrm{~nm}$ of TRPz decreases indicating 

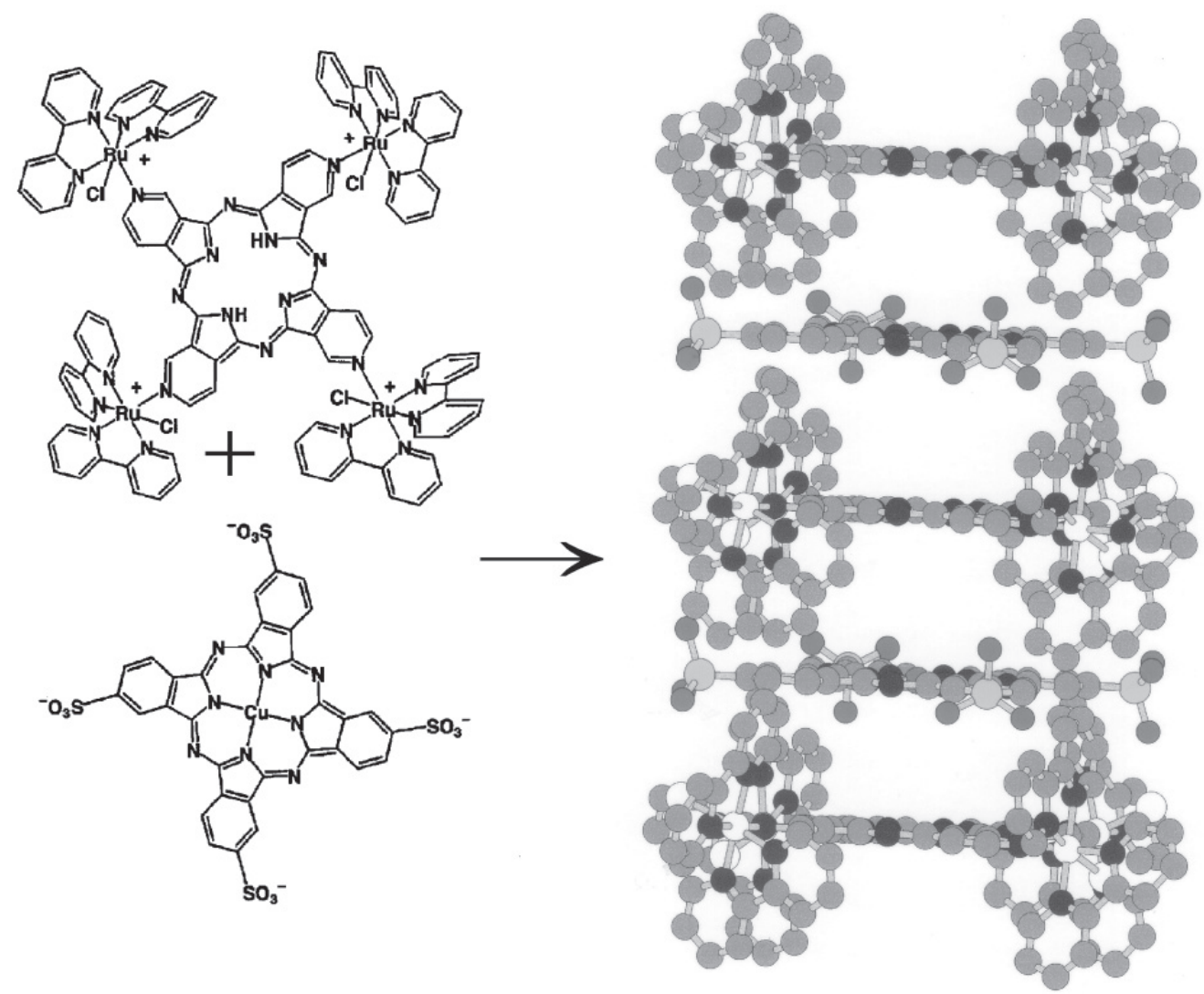

Figure 19. Illustration of the electrostatic/ $\pi$-stacking assembly of cationic TRPz and anionic tetrasulfonatephthalocyaninatecopper(II) complexes, CuTSPc, yielding the corresponding TRPz/CuTSPc double layered films.

stacked ion-pairing in solution. The plot of the absorbance at $710 \mathrm{~nm}$ as a function of the mole fraction of the interacting species shows a sharp end point at 1:1 mole ratio, as expected for a relatively strong interaction between those species. Suitable films of the TRPz/CuTSPC stacked ion-pairs have been generated in a controlled way, by alternating a dip-coating step, starting from methanolic TRPz followed by air drying, and another dip-coating step with aqueous CuTSPc, and rinsing with water. The films are similar to those obtained by mixing $\mu$-meso-tetra(4pyridyl)porphyrin \{tetrakis-chloro(bis bipyridine)ruthenium(II) $\}$ and meso-tetrasulfonatophenylporphyrins, ${ }^{119}$ however a contrasting aspect in the case of TRPz/CuTSPc films is that the electronic spectra of the two components are strongly affected, exhibiting a hypochromic shift and broadening of the Q band, as a consequence of the extended $\pi$ interaction throughout of the stacked TRPz/TSPc films.

Cyclic voltammetry of the TRPz species in solution exhibits four redox processes in the -1.6 to 1.2 range, as shown in Figure 20, ascribed to the $\mathrm{Ru}^{\mathrm{IIIIII}}$ redox pair at $\mathrm{E}_{1 / 2}=0.94 \mathrm{~V}$, and to the first and second reduction of the porphyrazine center at -0.63 and $-0.99 \mathrm{~V}$, followed by the bipy ${ }^{0 /-}$ couple around $-1.5 \mathrm{~V}$. However, based on spectro- electrochemical measurements for the TRPz species in solution (Figure 21), it has been shown that this wave is actually composite, involving the $\mathrm{Ru}^{\text {III/II }}$ redox pair, preceded by the oxidation of the porphyrazine center, around $0.7 \mathrm{~V}$.

The cyclic voltammograms of glassy carbon electrodes modified with TRPz alone or TRPz/CuTSPc layered films exhibit a pair of bell shaped waves at $0.9 \mathrm{~V}$, in LiTFMS aqueous solution (Figure 22). The peak currents increase linearly as a function of the scan rate, as expected for an electroactive species immobilized on the electrode surface. Cyclic voltammetry has been carried out in the presence of penta- and hexacyanoferrate complexes in order to probe the homogeneity and conductivity of the TRPz and TRPz/ CuTSPc films, as shown in Figure 21. When the potentials are scanned from $0.40 \mathrm{~V}$ to $1.2 \mathrm{~V}$ in the presence of $\left[\mathrm{Fe}^{\mathrm{II}}(\mathrm{CN})_{6}\right]$ and $\left[\mathrm{Fe}^{\mathrm{II}}(\mathrm{CN})_{5}\left(\mathrm{NH}_{3}\right)\right]$ complexes, no electrochemical response is observed at their normal redox potentials, i.e., 0.42 and $0.33 \mathrm{~V}$, respectively. However, a rather a sharp and intense anodic peak appears at the onset of the broad oxidation wave, around $0.70 \mathrm{~V}$. The current intensity of this electrochemical process is proportional to the square root of the scan rate, as expected for a diffusion controlled oxidation reaction at the modified electrode 


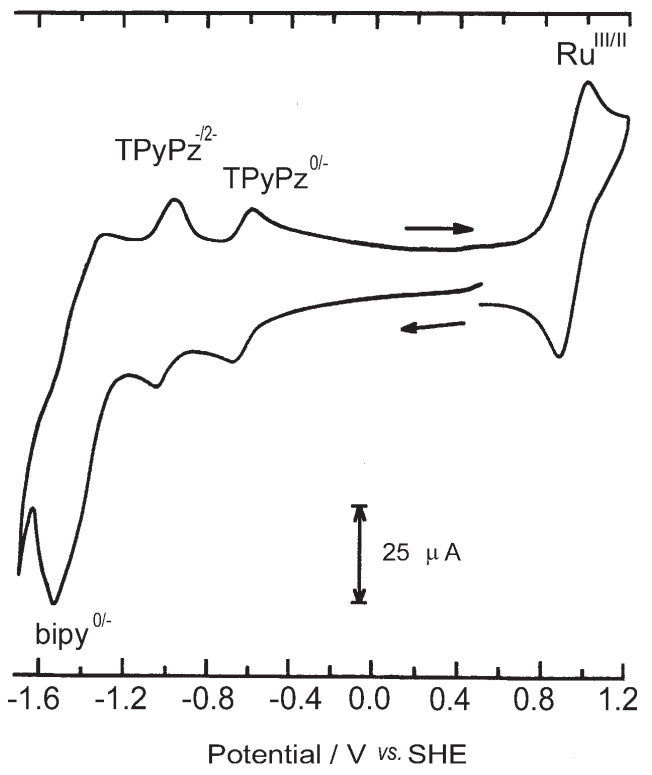

Figure 20. Cyclic voltammogram of the TRPz complex $\left(2.5 \mu \mathrm{mol} \mathrm{L}^{-1}\right)$ in DMF, scan rate $=200 \mathrm{mV} \mathrm{s}^{-1}$.

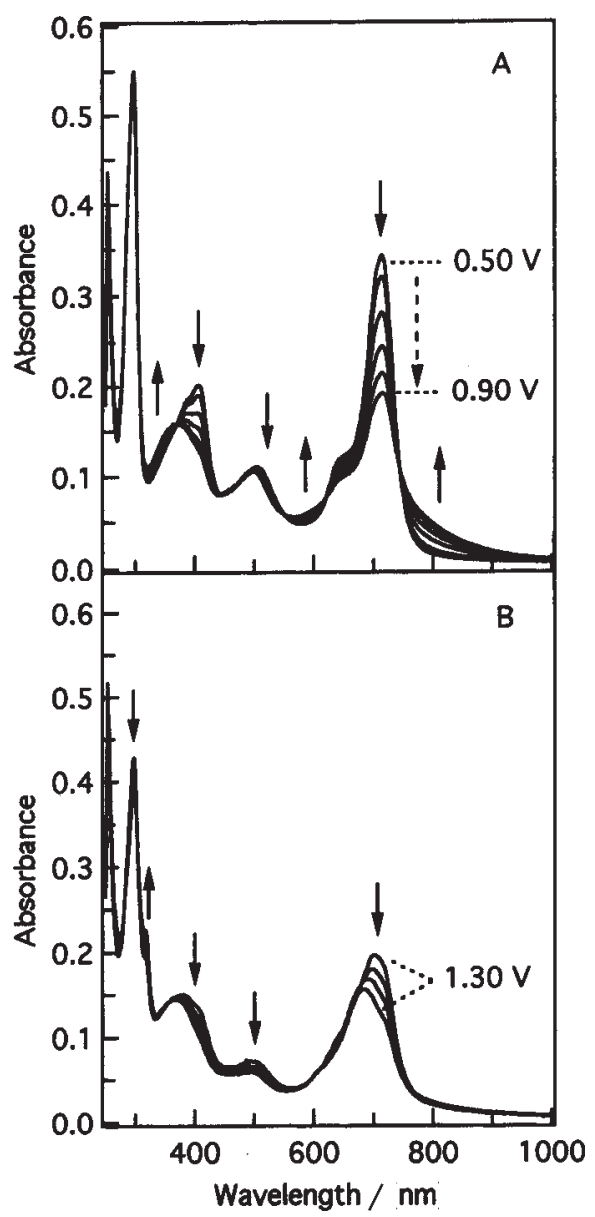

Figure 21. Spectroelectrochemical changes recorded for the TRPz species $\left(0.1 \mathrm{mmol} \mathrm{L}^{-1}\right)$ in the range from 0.50 to $1.30 \mathrm{~V}$, showing that the oxidation of the porphyrazine center (part A) precedes the oxidation of the peripheral ruthenium complexes above $1.0 \mathrm{~V}$ (part B). surface. The results are consistent with an electrochemical process mediated by the porphyrazine film, which act as a physical barrier for the approach of the cyanoferrate complexes from the glassy carbon electrode surface.

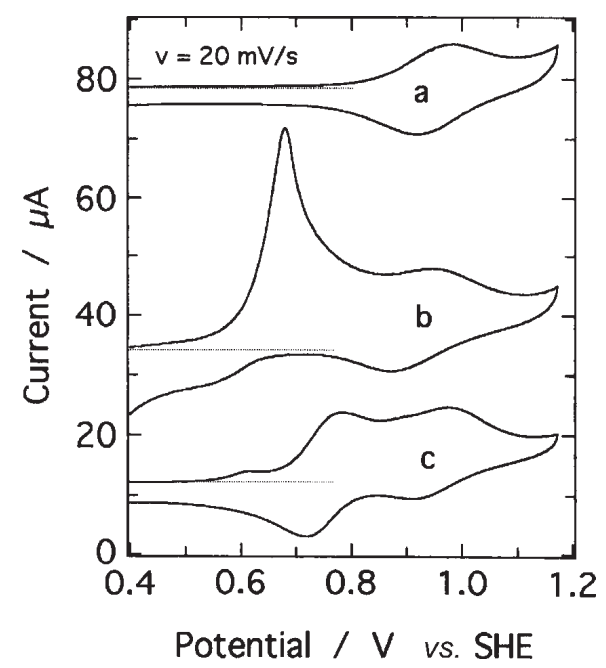

Figure 22. Cyclic voltammetry of TRPz/CuTSPc modified glassy carbon electrode in (a) lithium trifluoromethanesulfonate solution $\left(0.10 \mathrm{~mol} \mathrm{~L}^{-1}\right)$, and in the presence of (b) $\left[\mathrm{Fe}(\mathrm{CN})_{5} \mathrm{NH}_{3}\right]^{3-}$ solution $\left(5 \mathrm{mmol} \mathrm{L}^{-1}\right)$ or $(\mathrm{c})\left[\mathrm{Fe}(\mathrm{CN})_{5} \mathrm{MePz}\right]^{2-}$ solution $\left(5 \mathrm{mmol} \mathrm{L}^{-1}, \mathrm{MePz}=\right.$ $\mathrm{N}$-methylpyrazinium ion).

Since the modified films act as insulators below $0.70 \mathrm{~V}$, there is no response when the redox potentials of the reduced species in solution are lower than this value. When this limiting potential is reached, the film becomes conducting via $\mathrm{Ru}^{\mathrm{IIIIII}}$ electron hopping, and the reduced species can be rapidly oxidized, leading to a sharp, unidirectional, electrochemical response. In this case, an electric rectifier response is observed. ${ }^{120}$ It is interesting to note that when the redox potentials of the reduced species match the limit conducting values, e. g. $\mathrm{E}_{\mathrm{o}}>0.70 \mathrm{~V}$, the electric conduction becomes bidirectional, approaching a reversible type of electrochemical response. This expectation has been confirmed by using the (N-methylpyrazinium)pentacyanoferrate complex $\left(\mathrm{E}_{1 / 2}=\right.$ $0.75 \mathrm{~V} v s \mathrm{SHE})$, as shown in Figure 22.

In the impedance spectroscopy measurements for the TRPz/CuTSPc films, at $0.6 \mathrm{~V}$, the beginning of a semicircle is observed in the high-frequency region, followed by a very short diffusion controlled region and finally saturation (Figure 23). This kind of response can be associated with a Randles type circuit modified with a low frequency capacitor. This is evidence that the electrons are moving mainly by hopping mechanism and that the limiting step is the electron transfer rate from one redox site to the next one. However, at $0.95 \mathrm{~V}$, instead of one semicircle, the spectrum exhibited two, which can be 
associated with a capacitive and an inductive contribution at high frequencies. After these two kinetic controlled regions the system reaches a saturation regime, as can be seem by the almost vertical straight line in the low frequency region. The most important feature observed in that spectrum is the appearance of a second kinetic controlled region. The presence of capacitive and inductive components has been explained by considering that the electrons are moving in two different directions through the film and by distinct mechanisms. The fact that the film is constituted by strongly $\pi$ interacting, stacked porphyrazine and phthalocyanine species, facilitates the formation of columnar structures oriented perpendiculary to the electrode surface. According to spectroelectrochemistry, the stacks are being oxidized near the onset of the insulator/conductor switching potential. These are characteristics of porphyrin molecular wires that have been long studied by Ibers and co-workers ${ }^{121-123}$ The two kinetic controlled processes have been associated with an electron transfer from the peripheral ruthenium complexes to the central $\mathrm{p}$ stack and then through the stack until reaching the electrode surface.

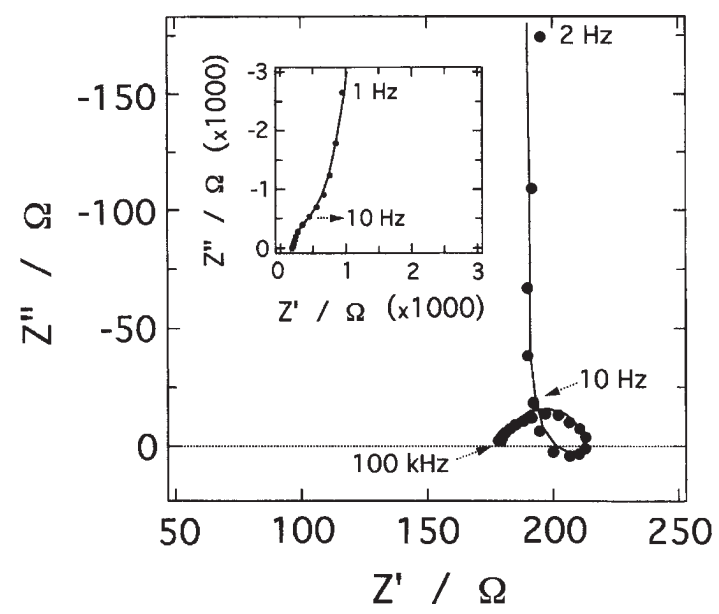

Figure 23. Nyquist plot of the experimental (solid circles) and simulated (solid line) impedance spectrum of TRPz/CuTSPc film modified ITO electrode, from $1 \mathrm{~Hz}$ to $100 \mathrm{kHz}$, at $0.95 \mathrm{~V}$ and $0.60 \mathrm{~V}$ (inset). Electrolyte: $0.10 \mathrm{~mol} \mathrm{~L}^{-1}$ lithium trifluoromethanesulfonate aqueous solution.

The modified electrodes of TRPz/CuTSPc films exhibited photoelectrochemical response in $\mathrm{O}_{2}$ saturated aqueous solution. ${ }^{118}$ The electrodes modified with bilayer films are active below $-0.05 \mathrm{~V}$ generating a reproducible photoelectrochemical response at $-0.4 \mathrm{~V}$ bias. The photoaction spectrum exhibits a broad band centered at $700 \mathrm{~nm}$ and a shoulder at 500, consistent with the Q and MLCT bands envelope. Its similarity with the absorption spectrum is a clear indication that the porphyrazine bilayer material is responsible for the observed photoelectrochemical activity. In fact, the electrodes modified with bilayer films are much more efficient, probably because of the faster electron transfer from the electrode to the film/solution interface. Presumably, the photocurrent response should be generated when the excited supramolecular system transfers electrons, reducing $\mathrm{O}_{2}$ to $\mathrm{H}_{2} \mathrm{O}_{2}$ or $\mathrm{H}_{2} \mathrm{O}$ and generating ruthenium(III) complexes, which are able to dope the $\pi$-stacked system increasing its conductivity and enhancing its photoaction response.

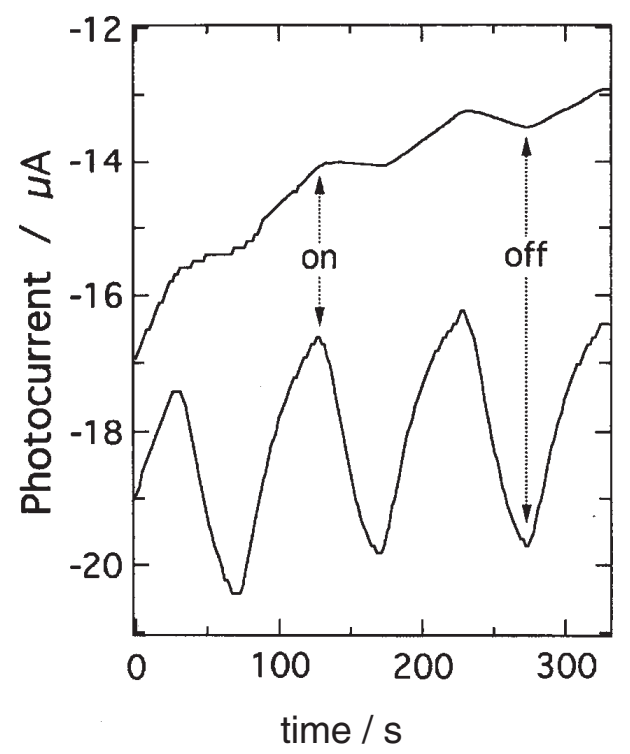

Figure 24. Photoelectrochemical response of TRPz (top) and TRPz/ CuTSPc (bottom) modified glassy carbon electrode in a lithium trifluoromethanesulfonate $\left(0.1 \mathrm{~mol} \mathrm{~L}^{-1}\right)$ aqueous solution satured with $\mathrm{O}_{2}$. On/Off indicates the beginning of irradiation/darkness steps.

\section{Multielectron Transfer Catalysis by Supramolecular Films of Tetracluster- Cobaltporphyrins}

The tetraelectronic reduction of $\mathrm{O}_{2}$ to water is a fundamental process carried out by the aerobic organisms, during the mitochondrial energy generation cycle. In general, the dioxygen reduction can proceed by bi- or tetraelectronic mechanisms, but the first one is by far more common. Typical cobalt porphyrins usually catalyze the dioxygen reduction yielding hydrogen peroxide instead to water. ${ }^{124}$ Outstanding research in this area has been carried out by Anson and co-workers along the last twenty years. ${ }^{125-127}$ Collman and co-workers ${ }^{128-131}$ have shown that the simultaneous interaction of the $\mathrm{O}_{2}$ molecule with two $\mathrm{CoP}$ centers is involved in the activation by a cofacial biscobaltporphyrin. However, more recently, they found out that the change of the electrode material from pyrolytic graphite to gold can switch the mechanism from tetraelec- 
tronic to bielectronic. ${ }^{131}$ Anson and co-workers, ${ }^{124-126,132-135}$ have studied cobalt meso-tetra(pyridyl) and meso-tetra(4cyanophenyl) porphyrins bound to $\left[\mathrm{Ru}\left(\mathrm{NH}_{3}\right)_{5}\right]^{2+}$ or $\left[\mathrm{Os}\left(\mathrm{NH}_{3}\right)_{5}\right]^{2+}$ ions, showing that the back-bonding from the ruthenium(II) and osmium(II) complexes plays an important role in the activation of the cobalt porphyrin center. ${ }^{136}$ On the other hand, they also showed that the $\left[\mathrm{Ru}\left(\mathrm{NH}_{3}\right)_{5}\right]^{2+}$ modified cobalt porphyrin becomes a bielectronic catalyst ${ }^{137}$ when in solution, revealing the importance of the electrode material or the arrangement of the molecules in the reaction pathway. Recently, however, a surprising efficiency has been reported for a rather simple molecule, such as the $(5,10,15,20$ tetramethylporphyrinato)cobalt(II) species. ${ }^{138}$

Previously, we have shown that the coordination of four $[\mathrm{Ru}(\mathrm{edta})]^{-}$complexes to iron and cobalt mesotetra(pyridyl)porphyrins enhances their catalytic activity toward $\mathrm{O}_{2}$ reduction in aqueous solution. ${ }^{102,103}$ This enhancement has been ascribed to the regeneration of the active $\mathrm{Co}^{\Pi \mathrm{P}}$ species by electron transfer from the reduced $\left[\mathrm{Ru}^{\mathrm{II}}(\mathrm{edta})\right]^{2-}$ complexes. However, the cobalt porphyrin remained a bielectronic catalyst. Along this line, a highly efficient, tetraelectronic catalyst based on a supramolecular meso-tetra(4-pyridyl)porphynato cobalto(III) complex containing four $\left[\mathrm{Ru}_{3} \mathrm{O}\left(\mathrm{CH}_{3} \mathrm{COO}\right)_{6}(\mathrm{py})_{2}\right]^{+}$clusters coordinated to the pyridyl substituents, CoTCP (Figure $16, \mathrm{M}=\mathrm{Co}$ ) has been recently reported. ${ }^{139}$

The CoTCP supermolecule exhibits a characteristic electronic spectrum (Figure 25) composed by the characteristic porphyrin Soret and Q bands at 435, and $557,611 \mathrm{~nm}$, respectively; and the ruthenium clusters bands at 318 and $693 \mathrm{~nm}$.

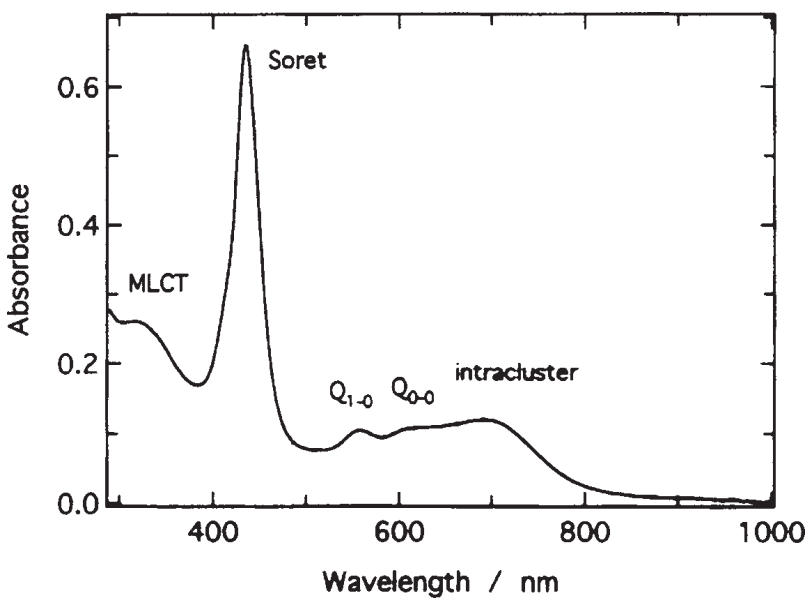

Figure 25. UV-Vis absorption spectrum of a $6.4 \times 10^{-6} \mathrm{~mol} \mathrm{~L}^{-1}$ CoTCP solution in acetonitrile. The assignment of the bands is indicated in the spectrum.

This supramolecular species forms stable films by dip coating, onto glassy carbon electrodes, exhibiting a reversible redox couple at $\mathrm{E}_{1 / 2}=0.22 \mathrm{~V}$ in aqueous solution (Figure 26). The adherence and durability of the modified electrodes are noteworthy. Typical surface concentration of $3.9 \times 10^{-10} \mathrm{~mol} \mathrm{~cm}^{-2}$ has been obtained from coulometric measurements, being consistent with a multilayered film.

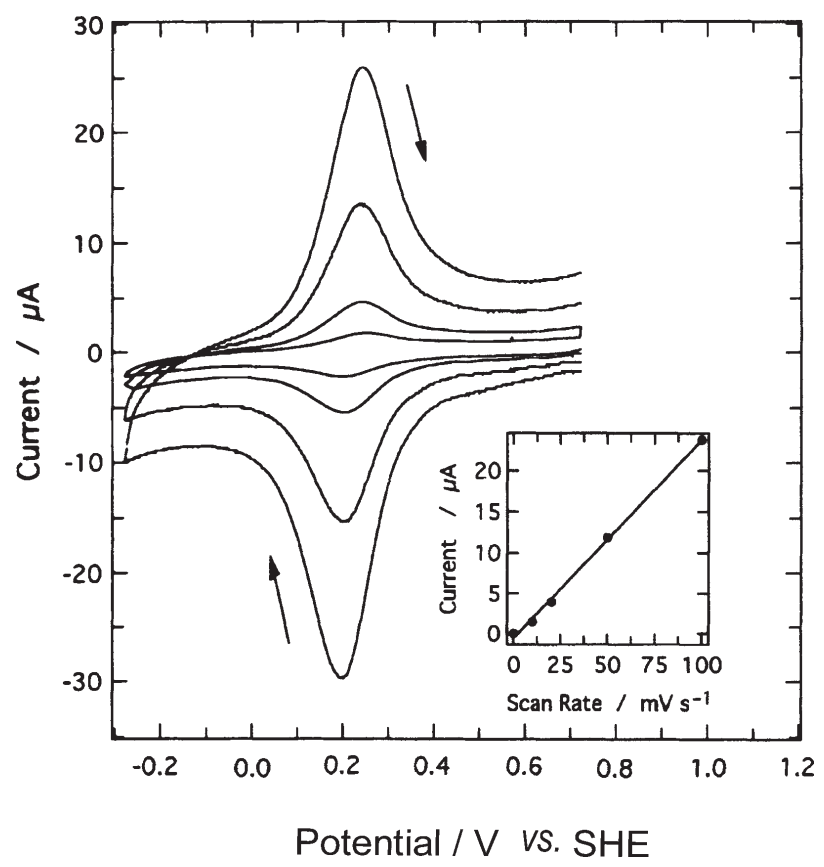

Figure 26. Cyclic voltammograms of a CoTCP modified glassy carbon electrode in $0.5 \mathrm{~mol} \mathrm{~L}^{-1} \mathrm{KNO}_{3}$ aqueous solution. Inset: plot of the peak current intensities as a function of the scan rate.

The spectrum of a film of CoTCP deposited onto a glassy carbon electrode surface is very similar to that of the molecular species in acetonitrile solution, but the Soret and Q bands are shifted respectively to 440, 555 and 610 $\mathrm{nm}$, and the intracluster band to $705 \mathrm{~nm}$. In comparison with the spectra of the films of supramolecular porphyrin coordinated to $\left[\mathrm{Ru} \text { (bipy) }{ }_{2} \mathrm{Cl}\right]^{+}$complexes, ${ }^{66,120,140}$ the CoTCP film spectrum is much less broadened. This is an evidence that in the films the cobalt porphyrin rings are too far to interact with each other, due to the bulkiness of the peripheral $\left[\mathrm{Ru}_{3} \mathrm{O}(\mathrm{OAc})_{6}(\mathrm{py})_{2}\right]^{+}$groups.

According to the spectroelectrochemistry measurements (Figure 27), there is an inversion in the potential order of the cluster $\left(\mathrm{Ru}^{\mathrm{III}} \mathrm{Ru}^{\mathrm{III}} \mathrm{Ru}^{\mathrm{III}} / \mathrm{Ru}^{\mathrm{II}} \mathrm{Ru}^{\mathrm{III}} \mathrm{Ru}^{\mathrm{II}}\right)$ and cobalt porphyrin $\left(\mathrm{Co}^{\mathrm{III} / \mathrm{II}} \mathrm{P}\right)$ redox processes, in comparison with the spectroelectrochemistry in acetonitrile solution. The inversion has been ascribed to the axial ligand exchange, when the solvent is changed from $\mathrm{ACN}$ to water. ${ }^{141} \mathrm{In}$ this system, the $\mathrm{E}_{0}$ values estimated using the spectroelectrochemistry data are 0.21 and 0.07 $\mathrm{V}$ for the $\mathrm{Ru}^{\mathrm{III}} \mathrm{Ru}^{\mathrm{III}} \mathrm{Ru}^{\mathrm{III} / \mathrm{Ru}}{ }^{\mathrm{II}} \mathrm{Ru}^{\mathrm{III}} \mathrm{Ru}^{\mathrm{II}}$ and $\mathrm{Co}^{\mathrm{III} / I I} \mathrm{P}$ redox pairs, respectively. 


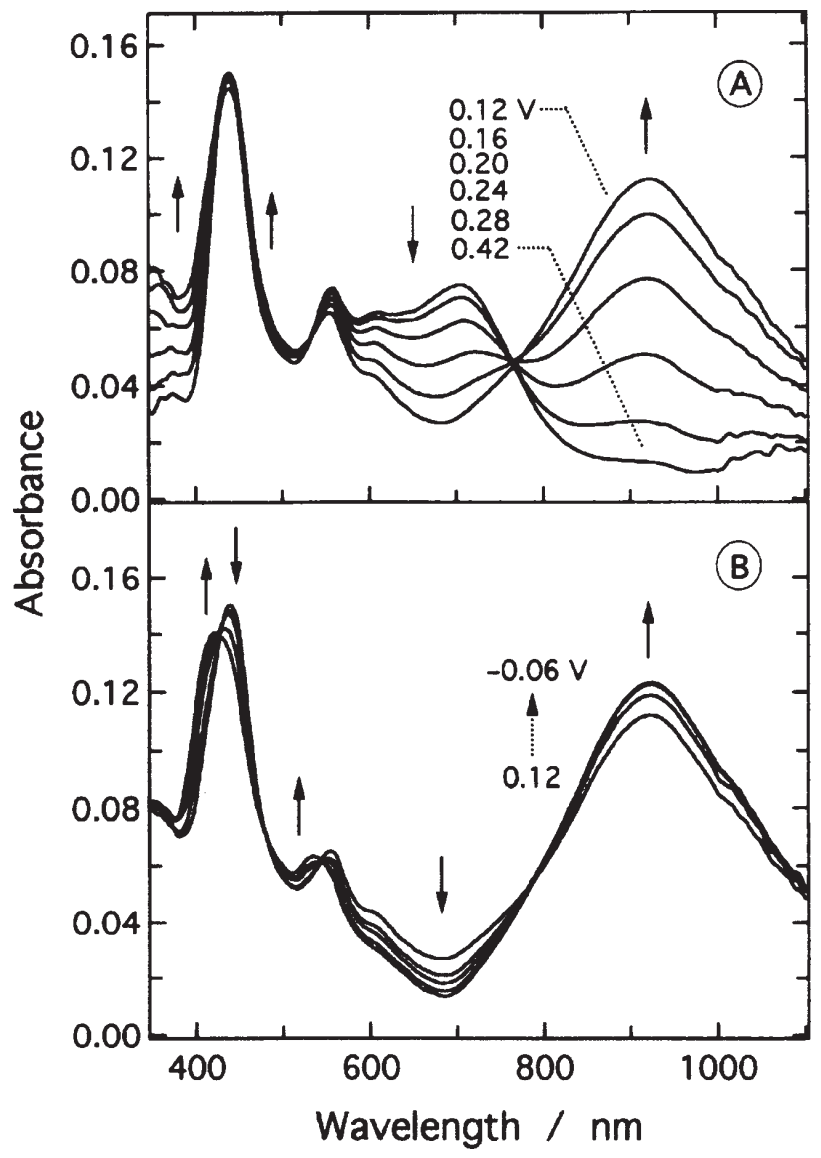

Figure 27. Spectroelectrochemistry of a film of CoTCP on a glassy carbon surface, showing (A) the $\mathrm{Ru}^{\mathrm{II}} \mathrm{Ru}^{\mathrm{II}} \mathrm{Ru}^{\mathrm{III}} / \mathrm{Ru}^{\mathrm{III}} \mathrm{Ru}^{\mathrm{II}} \mathrm{Ru}^{\mathrm{II}}$ process in the range from 0.12 to $0.42 \mathrm{~V}$ and $(\mathrm{B})$ the $\mathrm{Co}^{\text {III/II }}$ reduction in the range from -0.06 to $0.12 \mathrm{~V}$.

The cyclic voltammograms of $\mathrm{O}_{2}$ saturated aqueous solution, using a bare glassy carbon electrode exhibit a slow increase in the cathodic current below $-0.0 \mathrm{~V}$. In contrast, sharp and intense cathodic peaks around $0.2 \mathrm{~V}$ have been observed in the cyclic voltammograms of CoTCP modified glassy carbon electrodes, as shown in Figure 28. The catalytic wave is much more intense than

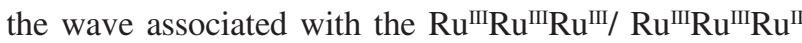
and $\mathrm{Co}^{\mathrm{III} / \mathrm{II}} \mathrm{P}$ redox pairs. The current intensities match the calculated peak currents for the reduction of the dioxygen to water $(n=4)$. In order to clarify the role of the ruthenium clusters on the catalytic activity, experiments with electrodes modified with ZnTCP, a zinc porphyrin derivative that lacks the cobalt porphyrin site, have been carried out in the same conditions. In this case the enhancement of the cathodic current in the 0.3 to $-0.0 \mathrm{~V}$ range is rather small, approaching the bare glassy carbon electrode response.

Rotating disc voltammograms recorded from 100 to $3000 \mathrm{rpm}$ are shown in Figure 29. All of them have a typical sigmoid shaped profile characteristic of a reversible

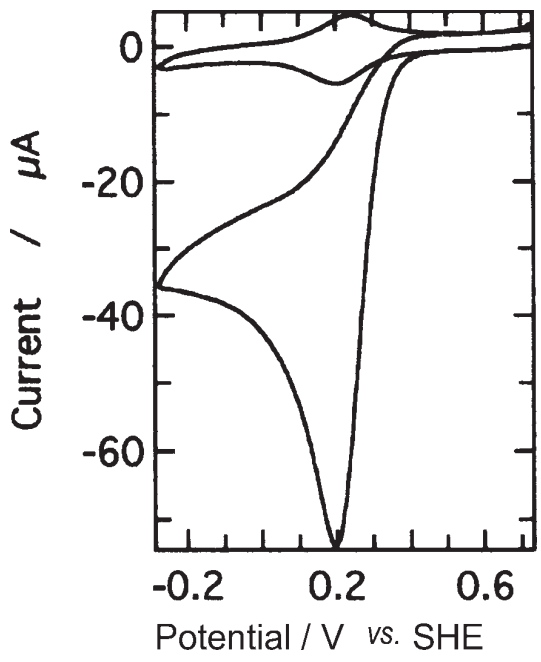

Figure 28. Cyclic voltammograms of the CoTCP modified electrode, scan rate $=20 \mathrm{mV} \mathrm{s}^{-1}$, in the absence (top) and presence of $\mathrm{O}_{2}$ (bottom)

electrochemical process. The Levich and Koutecky/Levich plots are linear up to $4000 \mathrm{rpm}$ and pass through the origin within experimental error. These are good evidence that the reaction rate is not limited by mass transport or electron diffusion through the film. In other words, the reduction proceeds as rapidly as the $\mathrm{O}_{2}$ molecules reach the film as can be inferred by the smooth current decay after the catalytic wave on the CV's and the flat plateau on the RDE voltammograms. The high current density $\left(2.8 \mathrm{~mA} / \mathrm{cm}^{2}\right.$ at $4000 \mathrm{rpm}$ ) achieved at the CoTCP modified electrodes is a good indication of the high efficiency of the catalytic reaction. Rotating ring disc electrochemical experiments

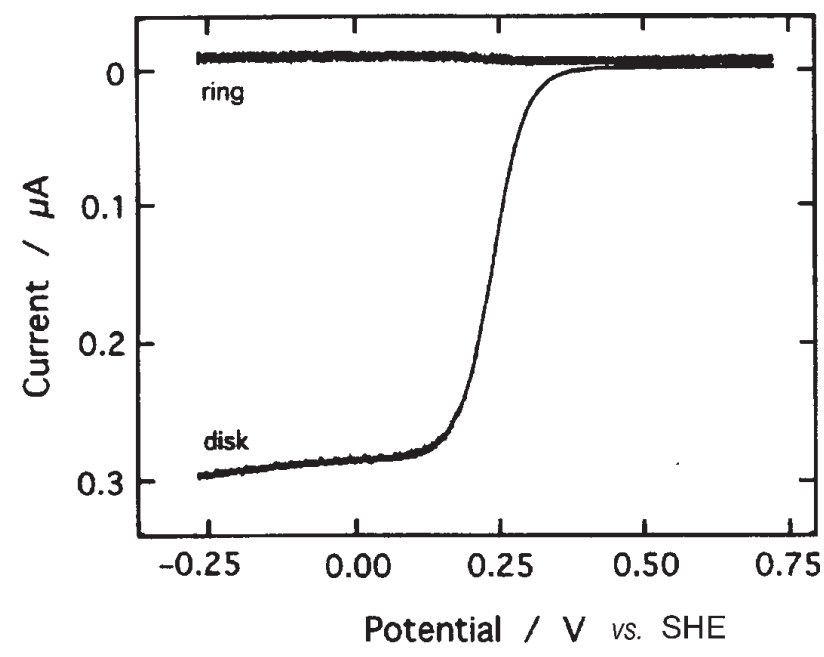

Figure 29. Rotating ring disk electrode voltammogram of a CoTCP modified glassy carbon electrode (disk scan rate $=10 \mathrm{mV} \mathrm{s}^{-1}, \omega=$ $1000 \mathrm{rpm}$ ) in a $\mathrm{O}_{2}$ saturated $0.50 \mathrm{~mol} \mathrm{~L}^{-1} \mathrm{KNO}_{3}$ aqueous solution, acetate buffer $0.05 \mathrm{~mol} \mathrm{~L}-1, \mathrm{pH}=4.7, \mathrm{~T}=25^{\circ} \mathrm{C}$. The potential of the platinum ring electrode was set to $1.22 \mathrm{~V}$ in order to oxidize $\mathrm{H}_{2} \mathrm{O}_{2}$. 
carried under the same experimental conditions have also been performed. No significant ring current has been measured, confirming the tetraelectronic reduction of the $\mathrm{O}_{2}$ molecules.

\section{Electropolymerized Films of Tetraruthenated Porphyrins as New Functional Electrochemical Materials}

By means of electropolymerization, ${ }^{142-148}$ molecular films can be deposited just on the polarized electrode surface, allowing to control the amount of deposited material. ${ }^{149-151}$ These characteristics can be very conveniently exploited for the preparation of arrays of modified electrodes. The strategy based on the electropolymerization of halogen substituted aromatic compounds has already been reported in the case of the reductive dimerization of 5-chlorophenanthroline (5-CIPhen) by Fussarydel et al. ${ }^{152}$ Following this approach, the corresponding porphyrin supermolecular species by attaching four $\left[\mathrm{Ru}(5-\mathrm{ClPhen})_{2} \mathrm{Cl}\right]^{+}$groups to the pyridine $\mathrm{N}$-atoms of $\mathrm{H}_{2}(\mathrm{TPy})$ have also been developed. Such species have been called ETRP (electropolymerizable tetraruthenated porphyrins). ${ }^{153}$

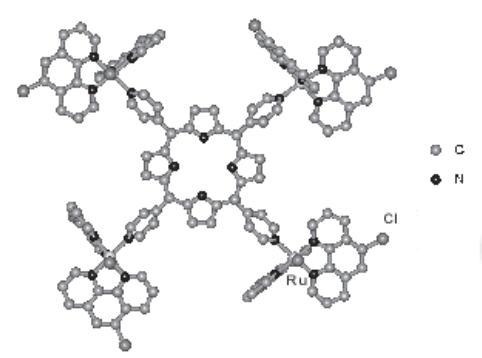

Figure 30. Structural representation of $\left[\mathrm{H}_{2}(4-\mathrm{TPyP})\{\mathrm{Ru}(5-\right.$ Clphen $\left.\left.{ }_{2} \mathrm{Cl}\right\}_{4}\right], \mathrm{H}_{2}$ (ETRP)

The UV-Vis spectra of $\mathrm{H}_{2}(\mathrm{ETRP})$ in methanol exhibits the characteristic porphyrin peaks at $419 \mathrm{~nm}$, and the Q bands at 513, 552, 588 and $648 \mathrm{~nm}$, in addition to an intense and narrow band at $295 \mathrm{~nm}$ and a broad band at $450 \mathrm{~nm}$, ascribed to the 5-Clphen $\pi-\pi^{*}$ intraligand and $\mathrm{Ru}^{\mathrm{II}}(\mathrm{d} \pi) \rightarrow 5$-Clphen ( $\left.\pi^{*}\right)$ MLCT transitions, respectively.

Four waves have been observed in the cyclic voltammograms of the supramolecular porphyrin species in DMF solution. The reversible waves at $\mathrm{E}_{1 / 2}=1.00$ and $-0.65 \mathrm{~V}$ have been assigned to the $\mathrm{Ru}(\mathrm{III} / \mathrm{II})$ redox pair and to the monoelectronic reduction of the porphyrin ring to the $\pi$-radical anion, respectively, while a shoulder at $\mathrm{E}_{\mathrm{pc}}=$ $-1.04 \mathrm{~V}$ corresponds to the formation of the respective porphyrin dianion. The monoelectronic reduction of a
5-Clphen ligand of each peripheral ruthenium complexes occurrs at $\mathrm{E}_{\mathrm{pc}}=-1.11 \mathrm{~V}$, as inferred by the higher current intensity and potential range of this wave. Its anodic wave seems to be broader, more intense and shifted to positive potentials because of the overlap with the anodic wave corresponding to the reoxidation of the porphyrin dianion.

A typical series of successive voltammograms in DMF ( -1.3 to $1.2 \mathrm{~V}$ range) using platinum disk electrodes are shown in Figure 31. The stepwise increase of the Ru(III/II) wave current as a function of the number of successive scans, reflect the electropolymerization process. ${ }^{149,154,155}$ It leads to a film resistant to washing with DMF and acetonitrile.

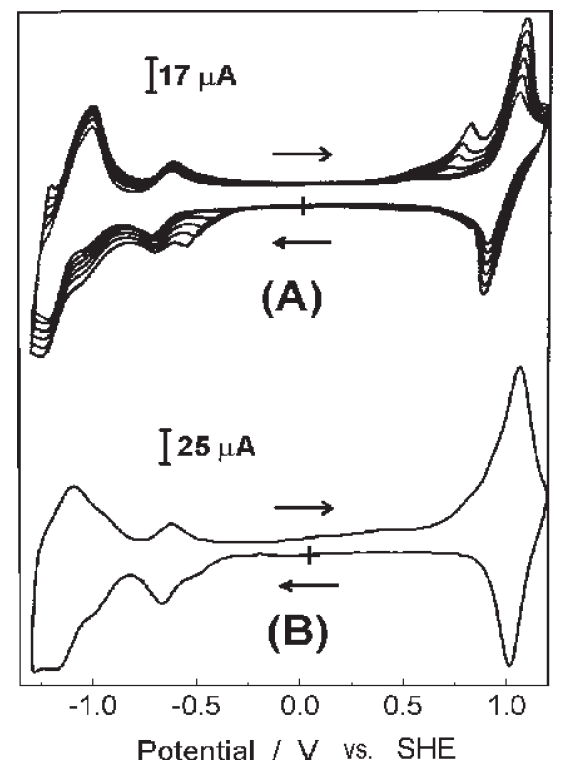

Figure 31. A) Successive cyclic voltammograms of $5.2 \times 10^{-4} \mathrm{~mol} \mathrm{~L}^{-1}$ ETRP in $0.2 \mathrm{~mol} \mathrm{~L}^{-1} \mathrm{TEAClO}_{4}$ DMF solution, scan rate $=100 \mathrm{mV} \mathrm{s}^{-1}, \mathrm{Pt}$ disk electrode. B) Cyclic voltammogram of a Pt electrode modified with a polymeric ETRP film obtained by electropolymerization of a dip-coated film, in $0.2 \mathrm{~mol} \mathrm{~L}^{-1} \mathrm{TEAClO}_{4}$ acetonitrile solution, scan rate $=100 \mathrm{mV} \mathrm{s}^{-1}$.

The reduction of the 5-ClPhen ligand induces the elimination of the phenanthroline chloro group as chloride anion and the formation of a radical species ${ }^{152}$ which reacts promptly with another radical, forming a dimer in the case of the free ligand. The $\mathrm{H}_{2}$ (ETRP) species has two of such ligand for each of the four peripheral ruthenium complexes. Consequently, just two of the eight 5-ClPhen ligands present in the porphyrin supermolecule are enough to form intramolecular $\mathrm{C}-\mathrm{C}$ bonds by this process, in order to generate a polymer. In fact, it has been observed that $\mathrm{H}_{2}$ (ETRP) can be directly electropolymerized from a DMF solution, but the deposition process is sluggish and the resultant films are rather unstable, due to the looseness of the polymeric chains in the structure. 
Considering that the new supermolecular porphyrin is able to form quite homogeneous films by dipcoating ${ }^{25,66,140,156}$ and that such films are poorly soluble in acetonitrile, a new procedure has been devised by carrying out the electropolymerization reaction on the preformed films, instead of from the molecular species in solution. ${ }^{153}$ The advantage is the high concentration of the monomer in the electrode surface and orientation of the monomer molecules, leading to a more compact and highly reticulated structure. Such aspects increase the efficiency of the electropolymerization process, since only one or two scans in the $0.0 \mathrm{~V}$ to -1.3 range are enough to promote the completion of the electropolymerization reaction. Another advantage of this process is that it requires only a minimum amount of the monomer, in contrast with the conventional electrodeposition procedure from a concentrated solution.

A typical bell shaped voltammogram of a platinum electrode modified with a thin polymeric $\mathrm{H}_{2}$ (ETRP) film in acetonitrile electrolyte solution is shown in Figure 31.B. The films deposited onto ITO by dip-coating solution has been examined by AFM microscopy, before and after the electropolymerization procedure. The AFM images (Figure 32) reveal that the dip-coated samples surface are formed by aggregates more or less uniformly distributed onto the ITO surface, while the electropolymerized films exhibit broad and regularly distributed features, reflecting the occurrence of structural changes and molecular reorganization, as depicted in Figure 33.
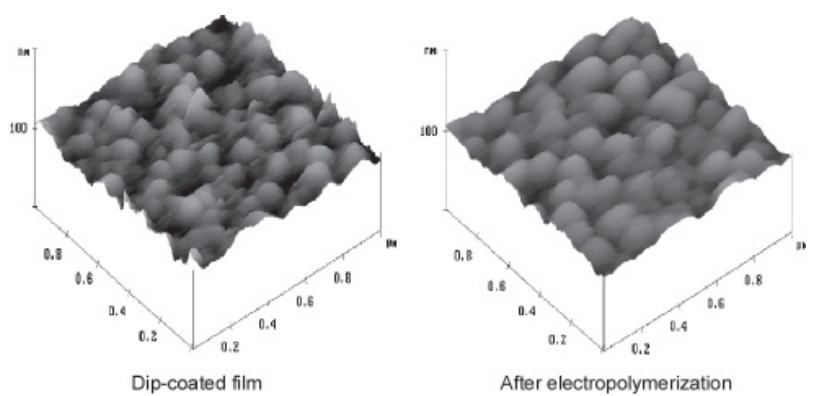

Figure 32. Morphology of the surface of a dip-coated film before and after electropolymerization (2 scans) in $\mathrm{TEAClO}_{4} 0.2 \mathrm{~mol} \mathrm{~L}^{-1}$ acetonitrile solution, in the -1.3 to $1.2 \mathrm{~V}$ range.

The conduction properties of the electropolymerized supermolecular porphyrin films ( 0.65 to $1.25 \mathrm{~V}$ range) have been probed by impedance spectroscopy. The Nyquist plots of the data obtained at different equilibrium potentials for $\Gamma=4 \times 10^{-9} \mathrm{~mol} \mathrm{~cm}^{-2}$ show that the impedance of the films is very high at potentials far from the $\mathrm{E}_{1 / 2}$ of the $\mathrm{Ru}(\mathrm{III} / \mathrm{II})$ redox pair. Only the activation controlled region (a fraction of a semicircle) is visible in that diagram. But, the charge transfer resistance decreases sharply as the applied potential

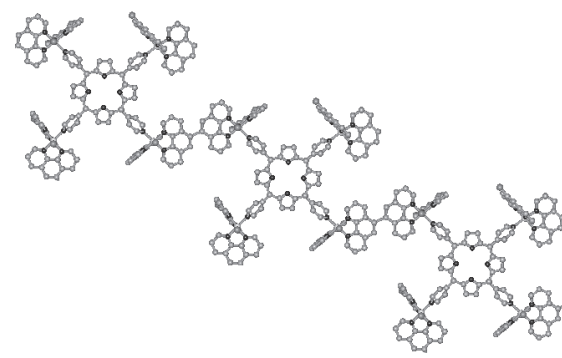

Figure 33. Simplified structural representation of the electropolymerized film, showing the formation of carbon-carbon bonds linking the several phenanthroline ligands.

approaches the $\mathrm{Ru}(\mathrm{III} / \mathrm{II})$ redox potential, defining the activation controlled, diffusion controlled and saturation regions characteristic of electrodes modified with thin electroactive films. ${ }^{157}$ When the potential is increased further, the impedance increases again, such that the profile of the conductance $v s$ potential plot reasonably matches the voltammetric wave profile. This behavior is typically explained by assuming a redox conduction mechanism. ${ }^{155,158}$ When the peripheral ruthenium complexes are totally reduced or oxidized, e.g. at 0.65 and $1.25 \mathrm{~V}$, the charge transfer impedance is high because of the low concentration of charge carriers. It reaches the minimum at the $\mathrm{E}_{1 / 2}$ when the concentration of the oxidized and the reduced species are equal.

The high background impedance of the electropolymerized porphyrin films contrasts with the relatively high intrinsic conductivity observed for the electrostatic assembled Co(TRPyP)/Zn(TPPS) bilayer films. ${ }^{159}$ In this case, a quite low electric resistance (about a $\mathrm{k} \Omega$ ) has been observed, becoming very low close to the $\mathrm{E}_{1 / 2}$ of the $\mathrm{Ru}(\mathrm{III} / \mathrm{II})$ redox pair. This difference arises from distinct molecular organization in those materials. In the case of the electrostatic assembled films, the porphyrin rings are forming stacks in which there is a considerable interaction between the extended $\pi$-clouds of that macrocycle, which should be responsible for the relatively high intrinsic conductivity. On the other hand, the $\mathrm{C}-\mathrm{C}$ bonds in the electropolymerized porphyrin films make the stacking of the porphyrin rings termodynamically unfavorable because of the angular tension. Consequently, the porphyrin rings are more randomly oriented in this material and there is less $\pi-\pi$ interaction between them, but the peripheral ruthenium complexes are sufficiently close to touch each other, allowing the occurrence of a fast and efficient electron hopping processes.

\section{Amperometric Sensors}

Sulfur dioxide and its source compounds, such as the 
sulfite salts, are widely used as preservatives in food industry. They are added to foods and beverages in order to inhibit bacterial growth, to prevent oxidation and inhibit discoloration, improving the final appearance of the products. ${ }^{160-162}$ In wine, sulfur dioxide is usually found either bound to unsaturated compounds and phenolic constituents, or as $\mathrm{HSO}_{3}, \mathrm{SO}_{3}{ }^{2-}$ and $\mathrm{SO}_{2}$. Only $\mathrm{SO}_{2}$ exhibits antiseptic properties. ${ }^{163,164}$ In spite of its relevance, the control of its amounts in wine is essential, because at high levels it produces a disagreeable aroma and taste, besides of being hazardous to human health. The maximum allowed levels of $\mathrm{SO}_{2}$ in wines are regulated by each country's legislation. In Brazil, for instance, the addition of 50 and $200 \mathrm{ppm}$ of free and bound $\mathrm{SO}_{2}$, respectively, is considered acceptable. ${ }^{165}$

In general, iodometric methods are preferred in industry for the determination of $\mathrm{SO}_{2}$. The results should be interpreted with caution because of the poor stability of the solutions and of the difficulties associated with the end point determination, particularly in the case of the red wines. Flow injection analysis (FIA) is becoming increasingly important in quality control because of its high sampling rate and simplicity, among other interesting features. Most of the FIA methods make use of a gasdiffusion cell to separate the sulfur dioxide released from the matrix compounds, through a semi-permeable membrane. The analyte can be determined with an optical detector, by monitoring its reaction with formaldehyde and p-rosaniline, in acidic solutions, ${ }^{166,167}$ or with electrochemical sensors. ${ }^{168,169}$.

Chemically modified electrodes constitute very attractive amperometric detectors for FIA, allowing the exploitation of the properties of the immobilized species and films. Recently, we reported a successful application of modified electrodes containing molecular films of tetraruthenated porphyrins, in flow injection analysis of NADH, dopamine, nitrite and sulfite ions. ${ }^{170,171}$ In those cases, in spite of the good performance of the modified electrodes as electrochemical detectors, a high concentration of trifluoromethanesulfonate or perchlorate counter ions is required to decrease the solubility and prevent the gradual leaching of the tetraruthenated porphyrins from the surface. This problem has been minimized by using electrodes modified with an alternating layers of cationic and anionic porphyrin films. ${ }^{172}$ The performance of this second generation of electrodes has been investigated in the analysis of free and total sulfur dioxide in wine, using a home made diffusion cell on line with the FIA amperometric detector. The gas diffusion cell is necessary for the transference of the gaseous compounds from the donor stream to the acceptor one, through a semipermeable membrane. For the build up of the amperometric detector, a glassy carbon electrode has been modified with alternating layers of CoTRP/ ZnTPPS films.

It should be mentioned that the detection of sulfite ions using conventional electrodes is usually complicated by a high overpotential and a poor electrochemical response. We have shown that CoTRP modified electrodes provide a considerable enhancement of the sulphite response and decrease of the overpotential. As a consequence of the electrocatalytical properties of the modified electrodes, the oxidation wave was cathodically shifted, approaching the $\mathrm{Ru}^{\mathrm{II} / I I I}$ redox couple potential $\left(+0.70 \mathrm{~V}\right.$ vs saturated $\left.\mathrm{Ag} / \mathrm{AgCl}_{\mathrm{KCl}}\right)$. A similar behavior has been observed for the electrostatically assembled CoTRP/ ZnTPPS films. ${ }^{140}$

Different types of wines (dry white, dry red and sweet white) have been analysed, including a home made red wine containing any preservative. The lack of detectable signal in this case indicates that the present analytical method is very reliable, excluding any interference from the natural constituents of wine. The agreement between the iodometric and FIA methods is quite good. However, the use of chemical sensors can be easily scaled up to a large number of samples and has all the advantages of the FIA methods. This is in contrast with the tedious and time consuming titration procedures.

Nitrite ion is another interesting analytical substrate because of its prevalence in industrialized meats as preserving agent and appearance builder. But, when ingested it can react with hemoglobin oxidizing it to metahemoglobin, and with amines converting them to nitrosamines, which are well-known carcinogenic substances. ${ }^{173,174}$ The environmental impact caused by the build-up of high nitrite and nitrate concentrations, owing to their use as fertilizers, and the problems caused by the contamination of water sources for human consumption are also big concerns. ${ }^{175}$

The capacity of being electropolymerized makes the $\mathrm{H}_{2}$ (ETRP) films rather interesting for that kind of application, specially for the preparation of microelectrode arrays, and because of their expected higher stability. A linear increase of the anodic current around $1 \mathrm{~V}$ has been observed in the cyclic voltammograms, as the concentration of nitrite was increased from $1 \times 10^{-4}$ to $8 \times 10^{-3} \mathrm{~mol} \mathrm{~L}^{-1}$, suggesting a quite a high activity, in spite of the higher electric impedance of the film. Consequently the oxidation of nitrite to nitrate is being mediated by the $\mathrm{Ru}$ (III) species electrochemically generated at the film. ${ }^{40,159,162,176}$ The kinetics of the mediated oxidation reaction of nitrite to nitrate has been studied by RDE voltammetry in the 200 
to $8000 \mathrm{rpm}$ rotation range, and $1 \times 10^{-5}$ to $1 \times 10^{-3} \mathrm{~mol} \mathrm{~L}^{-1}$ concentration range. The voltammograms exhibit a typical sigmoidal shaped profile characteristic of quite a rapid mediated reaction. The Levich plots presents a small but increasing curvature as the concentration of the substrate is increased at higher rotation rates. This is a clear indication that at these high mass transport conditions the current is no longer limited only by diffusion, but also by the kinetic of the heterogeneous electron transfer at the electrode surface. Accordingly, the corresponding rate constant has been obtained from the linear coefficients of the Koutech-Levich plots as $\mathrm{k}_{\mathrm{f}}=3.7 \times 10^{4} \mathrm{~mol} \mathrm{~L}^{-1} \mathrm{~s}^{-1}$ That value is one order of magnitude higher than that previously obtained ${ }^{150,176}$ for the Co(TRP)/Zn(TPPS) electrostatic assembled bilayer films, suggesting that the new material can be even more active than the previously studied materials.

Another important application of the nanostructured films of the supramolecular porphyrins is in the determination of acetaminophen in pharmaceutical formulations. This work has been recently performed ${ }^{177}$ by means of batch injection analysis (BIA) utilizing amperometric detection with glassy carbon electrodes modified with $\left[\mathrm{Co}(\mathrm{TPyP})\left\{\mathrm{Ru}(\text { bipy })_{2} \mathrm{Cl}\right\}_{4}\right]^{5+}$ triflate films.

In fact, BIA is an interesting alternative for application of electrodes modified with tetraruthenated porphyrins. This sensor exhibits sharp current response peaks, rapid washout and excellent reproducibility for BIA-amperometric quantification of acetaminophen. Also, a wide linear working range $\left(10^{-4}\right.$ to $\left.10^{-6} \mathrm{~mol} \mathrm{~L}^{-1}\right)$ as well as high sensibility and sampling frequency rate (detection limit = $1.1 \times 10^{-7} \mathrm{~mol} \mathrm{~L}^{-1}$, sampling frequency $=120$ injections $/ \mathrm{h}$ ); and a small volume of analysis ( $100 \mu \mathrm{L} /$ injection) has been achieved. The proposed method ${ }^{177}$ permits the direct and selective quantification of acetaminophen in many pharmaceutical products, avoiding cumbersome processes as previous separations, solvent extraction or sample filtration. Such new procedure has been applied to the analysis of commercial pharmaceutical products and the results were in excellent agreement with the ones obtained by standard spectrophotometric method.

\section{Conclusion}

By exploiting the strategies of coordination chemistry, versatile functional nanomaterials can be designed, conveying the remarkable characteristics of the metal centers, such as their electronic, optical and chemical properties, as well as all the characteristics of the ancillary ligands. Coordination chemistry also provides effective selfassembly strategies for molecular materials, based on specific metal-ligand affinity and stereochemistry. From the several molecular materials focused on this article, based on supramolecular porphyrins and porphyrazines, metalclusters and metal-polyimine complexes, an exciting field of investigation has been presented, covering a wide range of applications in catalysis, sensors and molecular devices.

\section{Acknowledgements}

The support from FAPESP, CNPq, RENAMI and the "Instituto do Milênio de Materiais Complexos" is gratefully acknowledged.

\section{References}

1. Feynman, R. P.; Engineering Science 1960, 23, 22.

2. Hipell, A.; The Molecular Designing of Materials and Devices, MIT Press: Cambridge, 1965, vol IV.

3. Drexler, K.; Engines of Creation: Challenges and Choices of the Last Technological Revolution, Anchor Press: New York, 1986.

4. Sheats, J. R.; Barbara, P. F.; Ac. Chem. Res. 1999, 32, 191.

5. Lehn, J. M.; Supramolecular Chemistry, VCH: Weinheim, 1995.

6. Atwood, J. R.; Davies, J. E. D; Macnicol, D. D.; Comprehensive Supramolecular Chemistry, Pergamon-Elsevier: New York, 1996.

7. Toma, H. E.; Quim. Nova 1991, 14, 189; Toma, H. E.; An. Acad. Brasil. Ci. 2000, 72, 1.

8. Belanger, S.; Hupp, J. T.; Stern, C. L.; Stone, R. V.; Watson, D. F.; Carrell, T. G.; J. Am. Chem. Soc. 1999, 121, 557.

9. Stoddart, J. F.; Acc. Chem. Res. 2001, 40, 2447.

10. Balzani, V.; Credi, A.; Raymo, F. M.; Stoddart, J. F.; Angew. Chem., Int. Ed. 2000, 39, 3349.

11. Cantrill, S. J.; Pease, A. R.; Stoddart, J. F.; J. Chem. Soc., Dalton 2000, 3715.

12. Pease, A. R.; Stoddart, J. F.; Struc. Bond. 2001, 99, 189.

13. Collier, C. P.; Jeppesen, J. O.; Luo, Y.; Perkins, J.; Wong, E. W.; Heath, R. J.; Stoddart, J.F.; J. Am. Chem. Soc, 2001, 123, 12632.

14. Luo, Y.; Collier, C. P.; Jeppesen, J. O; Nielsen, K. A.; Delonno E.; Ho, G.; Perkins, J.; Tseng, H. R.; Yamamoto, T.; Stoddart, J. F.; Heath, J. R.; ChemPhysChem 2002, 3, 519.

15. Balzani, V.; Credi, A.; Venturini, M.; Chem.-Eur. J. 2002, 8, 5524.

16. Balzani, V. Credi.; Venturini, M.; Proc. Natl. Acad. Sci. USA 2002, 99, 4814.

17. Whitesides, G. M.; Grzybowski, B.; Science 2002, 295, 2418.

18. Whitesides, G. M.; Sci. Am. 2001, 285, 78.

19. Lehn, J. M; Proc. Natl. Acad. Sci. USA 2002, 99, 4763; Machado, V. G.; Baxter, P. N. W.; Lehn, J.-M.; J. Braz. Chem. Soc. 2001, 12, 431. 
20. Lehn, J. M.; Polym. Int. 2002, 51, 825.

21. Schumaker, R. S.; US pat. 6,124,963, 2000.

22. Toma, H. E.; Araki, K.; Alexiou, A. D. P.; Nikolaou, S.; Dovidauskas, S.; Coord. Chem. Rev. 2001, 219, 187.

23. Toma, H. E.; Araki, K.; Coord. Chem. Rev. 2000, 196, 307.

24. Juris, A.; Balzani, V.; Barigelletti, F.; Campagna, S.; Belser, P.; Vonzelewsky, A.; Coord. Chem. Rev. 1988, 84, 85.

25. Kalyanasundaram, K.; Photochemistry of Polypyridine and Porphyrin Complexes, Academic Press: London, 1992.

26. Araki, K.; Toma, H. E.; Quim. Nova 2002, 25, 962.

27. Ward, M. D.; Chem. Soc. Rev. 1995, 24, 121

28. Fraysse, S.; Coudret, C.; Launay, J.-P.; Eur. J. Inorg. Chem. 2000, 1581

29. Masui, H.; Freda, A. L.; Zerner, M. C.; Lever, A. B. P.; Inorg. Chem. 2000, 39, 141.

30. Hossain, M. D.; Ueno, R.; Haga, M.; Inorg. Chem. Commun. 2000, 3, 35 .

31. Chao, H.; Ye, B. H.; Zhang, Q. L.; Ji, L. N.; Inorg. Chem. Commun. 1999, 2, 338.

32. Reimers, J. R.; Hush, N. S.; J. Phys. Chem. A 1999, 103, 3066.

33. Ward, M. D.; Chem. Ind. 1997, 640.

34. Neyhart, G. A.; Timpson, C. J.; Bates, W. D.; Meyer, T. J.; J. Am. Chem. Soc. 1996, 118, 3730.

35. Neyhart, G. A.; Hupp, J. T.; Curtis, J. C.; Timpson, C. J.; Meyer, T. J.; J. Am. Chem. Soc. 1996, 118, 3724.

36. Rocha, R. C.; Toma, H. E.; Inorg. Chem. Commun. 2001, 4, 230.

37. Rocha, R. C.; Araki, K.; Toma, H. E.; Transition Met. Chem. 1998, 23, 13.

38. Toma, H. E.; Giesbrecht, E.; Rojas, R. L. E.; Can. J. Chem. 1983, 61, 2520

39. Toma, H. E.; Giesbrecht, E.; Rojas, R. L. E.; J. Chem. Soc., Dalton 1985, 2469

40. Rocha, R. C.; Araki, K.; Toma, H. E.; Inorg. Chim. Acta 1999. 285, 197.

41. Rocha, R. C.; Toma, H. E.; Inorg. Chim. Acta 2000, 310, 65.

42. Rocha, R. C.; Toma, H. E.; Can. J. Chem. 2001, 79, 145.

43. Robin, M. B.; Day, P.; Adv. Inorg. Chem. Radiochem. 1967, 10, 247.

44. Haga, M. A.; Ali, M. M.; Koseki, S.; Fujimoto, K.; Yoshimura, K.; Nozaki, T.; Ohno, T.; Nakajima, K.; Stufkens, D. J.; Inorg. Chem. 1996, 35, 3335.

45. Haga, M.; Ano, T.; Kano, K.; Yamabe, S.; Inorg. Chem. 1991, $30,3843$.

46. Giuffrida, G.; Campagna, S.; Coord. Chem. Rev. 1994, 135, 517.

47. Toma, H. E.; Chavez-Gil, T. E.; Inorg. Chim. Acta 1997, 257, 197.

48. Toma, H. E.; Chavez-Gil, T. E.; Rocha, R. C.; Rechenberg, H. R.; J. Inclusion Phenom. 1999, 34, 57.

49. Balzani, V.; Scandola, F.; Supramolecular Photochemistry, Harwood: West Sussex, 1991.
50. Schlicke, B.; Belser, P.; Cola, L. De; Sabbioni, E.; Balzani, V; J. Am. Chem. Soc. 1999 121, 4207.

51. Baudin, H. B.; Davidsson, J.; Serroni, S.; Juris, A.; Balzani, V.; Campagna, S.; Hammarstrom, L.; J. Phys. Chem. A 2002, 106, 4312.

52. Vogtle, F.; Plevoets, M.; Nieger, M.; Azzellini, G. C.; Credi, A.; De Cola, L.; De Marchis, V.; Venturi, M.; Balzani, V.; J. Am. Chem. Soc. 1999, 121, 6290.

53. Belser, P.; Bernhard, S.; Blum, C.; Beyeler, A.; Cola, L. De, Balzani, V.; Coord. Chem. Rev. 1999, 190, 155.

54. Balzani, V.; Juris, A.; Coord. Chem. Rev. 2001, 211, 97.

55. Barigelletti, F.; Flamigni, L.; Guardigli, M.; Juris, A.; Beley, M.; Chodorowski-Kimmes, S.; Collin, J.-P.; Sauvage, J.-P.; Inorg. Chem. 1996, 35, 136.

56. Camera, S. G.; Toma, H. E.; J. Photochem. Photobiol. A 2002, $151,57$.

57. Toma, H. E.; Lever, A. B. P; Inorg. Chem. 1986, 25, 176.

58. Toma, H. E.; Alburn, P. A.; Dodsworth, E. S.; Golovin, M. N.; Lever, A. B. P.; Inorg. Chem. 1987, 26, 4257.

59. Toma, H. E.; Santos, P. S.; Lever, A. B. P.; Inorg. Chem. 1988, 27, 3850

60. Berg-Brennan, C.; Subramanian, P.; Absi, M.; Stern, C.; Hupp, J. T.; Inorg. Chem., 1996, 35, 3719.

61. Cola, L.; Belser, P.; Coord. Chem. Rev. 1998, 177, 301.

62. Bergonzi, R.; Fabbrizzi, L.; Licchelli, M.; Mangano, C.; Coord. Chem. Rev. 1998, 170, 31.

63. Indelli, M. T.; Scandola, F.; Collin, J. P.; Sauvage, J. P.; Inorg. Chem. 1996, 35, 303.

64. Lee, J. D.; Vrana, L. M.; Bullock, E. R.; Brewer, K. J.; Inorg. Chem. 1998, 37, 3575.

65. Indelli, M. T.; Bignozzi, C. A.; Harriman, A.; Schnoover, R. J.; Scandola, F.; J. Am. Chem. Soc. 1994, 116, 3768.

66. Araki, K.; Toma, H. E.; J. Photochem. Photobiol. A 1994, 83, 245.

67. Bensasson, R. V.; Land, E. J.; Moore, A. L.; Crouch, R. L.; Dirks, G.; Moore, T. A.; Gust, D.; Nature 1981, 290, 329.

68. Bignozzi, C. A.; Argazzi, R.; Chiorboli, C.; Roffia, S.; Scandola, F.; Coord. Chem. Rev. 1991, 111, 261.

69. Carbonera, D.; Valentin, M. Di; Agostini, G,; Giacometti, G.; Liddell, P. A.; Gust, D.; Moore, A. L.; Moore, T. A.; Appl. Magn. Reson. 1997, 13, 487.

70. Plevoets, M.; Vogtle, F.; Cola, L. De; Balzani, V.; New J. Chem. 1999, 23, 63 .

71. Toyama, M. M.; Franco, M.; Catalani, L. H.; Araki, K.; Toma, H. E.; J. Photochem. Photobiol. A 1998, 118, 11.

72. Wasielewski, M. R.; Liddell, P. A.; Barrett, D.; Moore, T. A.; Gust, D.; Nature 1986, 322, 570.

73. Whitten, D. G.; Spooner, S. P.; Hsu, Y.; Penner, T. L.; React. Polym. 1991, 15, 37.

74. Wasielewski, M. R.; Chem. Rev. 1992, 92, 435.

75. Clayton, A. H. A.; Ghiggino, K. P.; Lawson, J. M.; Paddonrow, M. N.; J. Photochem. Photobiol. A 1994, 80, 323. 
76. Harriman, A.; Hissler, M.; Trompette, O.; Ziessel, R.; J. Am. Chem. Soc. 1999, 121, 2516.

77. LeGourrierec, D.; Andersson, M.; Davidsson, J.; Mukhtar, E.; Sun, L. C.; Hammarstrom, L.; J. Phys. Chem. A 1999, 103, 557.

78. Lehn, J. M.; Angew. Chem., Int. Ed. 1988, 27, 89; B. Alpha; R. Ballardini; V. Balzani; J. M. Lehn; S. Perathoner; N. Sabbatini; Photochem. Photobiol. 1990, 146, 347; B. Alpha; V. Balzani; J. M. Lehn; S. Perathoner; N. Sabbatini; Angew. Chem. Int. Ed. 1987, 26, 1266; G. Blasse; G. J. Dirksen; N. Sabbatini; S. Perathoner; J. M. Lehn; B. Alpha; J. Phys. Chem. 1988, 92 , 2419.

79. Bagatin, I. A.; Toma, H. E.; New J. Chem. 2000, 24, 841.

80. Gameiro, C. G.; Achete, C. A.; Simão, R. A.; Da Silva, E. F.; Santa-Cruz, P. A.; J. Alloy Compd. 2002, 344, 385.

81. Gameiro, C. G.; Da Silva, E. F.; Alves, S.; De Sa, G. F.; SantaCruz, P. A.; J. Alloy Compd. 2001, 323, 820.

82. Gameiro, C. G.; Da Silva, E. F.; Alves, S.; De Sa, G. F.; SantaCruz, P. A.; Mater. Sci Forum 1999, 315, 249.

83. Hu, Y. Z.; Tsukiji, S.; Shinkai, S.; Oishi, S.; Hamachi, I.; J. Am. Chem. Soc. 2000, 122, 241.

84. Araki, K.; Losco, P.; Engelmann, F. M.; Winnischofer, H.; Toma, H. E.; J. Photochem. Photobiol. A 2001, 142, 25.

85. Flamini, L.; Barigelletti, F.; Armaroli, N.; Collin, J. P.; Dixon, I. M.; Sauvage, J. P.; Williams, J. A. G.; Coord. Chem. Rev. 1999, 192, 671.

86. Onuki, J.; Ribas, A. V.; Medeiros, M. H. G.; Araki, K.; Toma, H. E.; Catalani, L. H.; Di Mascio, P.; Photochem. Photobiol. 1996, 63, 273.

87. Vincendo, P., Mouysset, S.; Paillous, N.; Photochem. Photobiol. 1997, 65, 647.

88. Barton J. K.; Raphael, A. L.; J. Am. Chem. Soc. 1984, 106 2466.

89. Fiel, R. J.; J. Biomol. Struc.Dyn. 1989, 6 , 1259.

90 Fiel, R. J.; Howard, J. C.; Mark, E. H.; Gupta, N. D.; Nucleic Acids Res. 1979, 6, 3093.

91. Marzilli, L. G.; New J. Chem. 1990, 14, 409.

92. Dougherty, T. J.; Gomer, C. J.; Henderson, B. W.; Jori, G.; Kessel, D.; Korbelik, M.; Moan, J.; Peng, Q.; J. Natl. Cancer Inst. 1998, 90, 889.

93. Henderson, B. W.; Dougherty, T. J.; Photochem. Photobiol. 1992, 55, 145.

94. Foote, C. S; Photochem. Photobiol. 1991, 54, 659.

95. Araki, K.; Silva, C. A.; Toma, H. E.; Catalani, L. H.; Medeiros, M. H. G.; Di Mascio, P.; J. Inorg. Biochem. 2000, 78, 269.

96. Ravanat, J.-L.; Berger, M.; Benard, F.; Langois, R.; Oullet, R.; van Lier, J. E.; Cadet, J.; Photochem. Photobiol. 1992, 55, 809.

97. Adam, W.; Saha-Möller, C. R.; Schönberger, A.; J. Am. Chem. Soc. 1997, $119,719$.

98. Ravanat, J. L.; Cadet, J.; Araki, K.; Toma, H. E.; Medeiros, M. H. G.; Di Mascio, P.; Photochem. Photobiol. 1998, 68, 698.
99. Gunter, M. J.; Turner, P.; Coord Chem. Rev. 1991, 108, 115. 100. Meunier, B.; Chem. Rev. 1992, 92, 1411.

101. Araki, K.; Toma, H. E.; J. Chem. Res. (M) 1994, 1501.

102. Araki, K.; Toma, H. E.; Inorg. Chim. Acta 1991, 179, 293.

103. Toma, H. E.; Araki, K.; J. Chem. Res. (S) 1990, 83.

104. Alexiou, A. D. P.; Toma, H. E.; J. Chem. Res. (S) 1993, 464.

105. Toma, H. E.; Cunha, C. J.; Cipriano, C.; Inorg. Chim. Acta 1988, 154, 63

106. Toma, H. E.; Alexiou, A. D. P.; Electrochim. Acta, 1993, 38 , 975.

107. Araujo, J. Jr.; Nikolaou, S.; Alexiou, A.D.P.; Toma, H.E.; Monatsh. Chem. 1997, 128759

108. Alexiou, A. D. P; Toma, H. E.; J. Chem. Res. (S) 1997, 338.

109 Toma, H.E.; Cunha, C.J.; Can. J. Chem. 1989, 67, 1632.

110. Toma, H.E.; Cipriano, C.; J. Electroanal. Chem. 1989, 263 , 313.

111. Toma, H. E.; Araki, K.; Silva, E. O.; Monatsh. Chem. 1998 , 129, 975.

112. Dovidauskas, S.; Toma, H. E.; Araki, K.; Sacco, H. C.; Iamamoto, Y.; Inorg. Chim. Acta 2000, 305, 206.

113. Jin, N.; Groves, J.T.; J. Am. Chem. Soc. 1999, 121, 2923.

114. Sorokin, A.; Robert, A.; Meunier, B.; J. Am. Chem. Soc. 1993, 115,7293

115. Czernuszewicz, R.S.; Su, Y.O.; Stern, M.K.; Macor, K.A.; Kim, D.; Groves, J.T.; Spiro, T.G; J. Am. Chem. Soc. 1988, 110, 4158

116. Smegal, J.A.; Hill, C.L.; J. Am. Chem. Soc. 1983, 105, 3515.

117. Toyama, M.M.; Araki, K.; Toma, H.E.; Spectrosc. Lett. 1998, 31, 1065.

118. Araki, K.; Wagner, M.J.; Wrighton, M.S.; Langmuir 1996, 12, 5393.

119. Araki, K.; Toma, H.E.; Electrochim. Acta 1999, 44, 1577.

120. Araki, K.; Angnes, L.; Toma, H.E.; Adv. Mater. 1995, 7, 554

121. Palmer, S.M.; Stanton, J.L.; Jaggi, N.K.; Hoffman, B.M.; Ibers, J.A.; Schwartz, L.H.; Inorg. Chem. 1985, 24, 2040.

122. Newcomb, T.M.; Godfrey, M.R.; Hoffman, B.M.; Ibers, J.A.; J. Am. Chem. Soc. 1989, 111, 7078

123. Newcomb, T.P.; Godfrey, M.R.; Hoffman, B.M.; Ibers, J.A.; Inorg. Chem. 1990, 29, 223.

124. Shi, C.N.; Anson, F. C.; Inorg. Chem. 1992, 31, 5078.

125. Steiger, B.; Shi, C.N.; Anson, F. C.; Inorg. Chem. 1993, 32, 2107.

126. Anson, F. C.; Shi, C.N.; Steiger, B.; Acc. Chem. Res. 1997, 30 , 437.

127. Song, E. H.; Shi, C. N.; Anson, F. C.; Langmuir 1998, 14 , 4315 .

128. Collman, J. P.; Marrocco, M.; Denisevich, P.; Koval, C.; Anson, F. C.; J. Electronal. Chem. 1979, 101, 117.

129. Collman, J. P.; Denisevich, P.; Konai, Y.; Marrocco, M.; Koval, C.; Anson, F. C.; J. Am. Chem. Soc. 1980, 102, 6027

130. Durand, R. R.; Bencosme, C. S.; Collman, J. P.; Anson, F. C.; J. Am. Chem. Soc. 1983, 105, 2710. 
131. Collman, J. P.; Inorg. Chem. 1997, 36, 5145.

132. Shi, C. N.; Anson, F. C.; J. Am. Chem. Soc. 1991, 113, 9564.

133. Shi, C. N.; Anson, F. C.; Inorg. Chim. Acta 1994, 225, 215.

134. Steiger, B.; Anson, F. C.; Inorg. Chem. 1995, 34, 3355.

135. Steiger, B.; Anson, F. C.; Inorg. Chem. 1997, 36, 4138.

136. Steiger, B.; Anson, F. C.; J. Porphyrins Phtalocyanines 1999, 3, 159.

137. Shi, C. N.; Anson, F. C.; Inorg. Chem. 1995, 34, 4554.

138. Shi, C. N.; Anson, F. C.; Inorg. Chem. 1998, 37, 1037.

139. Araki, K.; Dovidauskas, S.; Winnischofer, H.; Alexiou, A. D. P.; Toma, H. E.; J. Electroanal. Chem. 2001, 498, 152.

140. Araki, K.; Angnes, L.; Azevedo, C. M. N.; Toma, H. E.; J. Electroanal. Chem. 1995, 397, 205.

141. Truxillo, L.A.; Davis, D.G.; Anal. Chem. 1975, 47, 2260.

142. VilchezAguado F.; GutierrezGranados, S.; SucarSuccar S.; BiedCharreton, C.; Bedioui, F.; New J. Chem. 1997, 21, 1009.

143. Shimidzu, T.; Polym. Adv. Technol. 1997, 8, 275.

144. Deronzier, A.; Devaux, R.; Limosin, D.; Latour, J.M.; J. Electroanal. Chem. 1992, 324, 325.

145. Schaferling, M.; Bauerle, P.; Synth. Met. 2001, 119, 289.

146. Diab, N.; Schuhmann, W.; Electrochim. Acta 2001, 47, 265.

147. Bruti, E.M.; Giannetto, M.; Mori, G.; Seeber, R.; Electroanalysis 1999, 11, 565.

148. Volf, R.; Shishkanova, T.V.; Kral, V.; J. Inclusion Phenom. Macrocyclic Chem. 1999, 35, 111.

149. Takada, K.; Storrier, G.D.; Goldsmith, J.I.; Abruna, H.D.; J. Phys. Chem. B 2001, 105, 2404.

150. Bommarito, S.L.; Lowerybretz, S.P.; Abruna, H.D.; Inorg. Chem. 1992, 31, 502.

151. Takada, K.; Storrier, G.D.; Pariente, F.; Abruna, H.D.; J. Phys. Chem. B 1998, 102, 1387.

152. Fussarydel, O.; Zhang, H.T.; Hupp, J.T.; Leidner, C.R.; Inorg. Chem. 1989, 28, 1533.

153. Winnischofer, H.; Lima, S. S.; Araki, K.; Toma, H. E.; Anal. Chim. Acta 2003, 480, 97.

154. Kuester, S.N.; McGuire,M.M.; Drew, S. M; J. Electroanal. Chem. 1998, 452, 13.

155. Bommarito, S. L.; Lowerybretz, S.P.; Abruna, H.D.; Synlett 1993, 375.

156. Araki, K.; Toma, H.E.; J. Coord. Chem. 1993, 30, 9.

157. Armstrong, R.D.; Lindholm, B.; Sharp, M.; J. Electroanal. Chem. 1986, 202, 69.
158. Andrieux, C.P.; Haas, O.; Saveant, J.M.; J. Am. Chem. Soc. 1986, 108,8175 .

159. Rocha, J.R.C.; Angnes, L.; Bertotti, M.; Araki, K.; Toma, H.E.; Anal. Chim. Acta 2002, 452, 23.

160. Coker, L. E.; J. Assoc. Off. Anal. Chem. 1986, 69, 8.

161. Moylan, J. G.; Bowes, F. W.; Pappin, W. J.; J. Assoc. Off. Anal. Chem., 1986, 69, 11.

162. Ough, C. S.; Tratado Basico de Enología, Acribia: Zaragoza, 1996.

163. Ough, C. S.; J. Assoc. Off. Anal. Chem, 1986, 69, 5-7.

164. Gomes, M. T.; Rocha, T. A.; Duarte, A. C.; Oliveira, J. P.; Anal. Chem. 1996, 68, 1561.

165. Normas de Qualidade para Alimento, Instituto Adolfo Lutz: São Paulo, 1976, vol. 6.

166. Linares, P.; Luque de Castro, M. D.; Valcárcel, M.; Anal. Chim. Acta, 1989, 225, 443.

167. Zhi, Z.; Ríos, A.; Valcárcel, M.; Analyst 1995, 120, 2013.

168. Decnop-Weever, L. G.; Kraak, J. C.; Anal. Chim. Acta 1997, $337,125$.

169. Cardwell, T. J.; Cattrall, R. W.; Chen, G. N.; Scollary, G. R.; Hamilton, I. C.; Analyst 1991, 116, 253.

170. Granados, M.; Maspoch, S.; Blanco, M.; Anal. Chim. Acta 1986, 179, 445.

171. Angnes, L.; Azevedo, C. M. N.; Araki, K.; Toma, H. E.; Anal. Chim. Acta 1996, 329, 91.

172. Azevedo, C. M. N.; Araki, K.; Angnes, L.; Toma, H. E.; Electroanalysis 1998, 10, 467.

173. Huang, Y. G.; Ji, J. D.; Hou, Q. N.; Mutat. Res. 1996, 358, 7.

174. Wolff, I. A.; Wassema, A. E.; Science 1972, 177, 15.

175. Williams, A. E.; Johnson, J. A.; Lund, I. J.; Kabala, Z. J.; J. Environ. Qual. 1998, 27, 1147.

176. Rocha, J. R. C.; Demets, G. J. -F.; Bertotti, M.; Araki, K.; Toma, H. E.; J. Electroanal. Chem. 2002, 526, 69.

177. Quintino, M. S.; Araki, K.; Toma, H. E.; Angnes, L.; Electroanalysis 2002, 14, 1236.

Received: March 24, 2003

Published on the web: October 15, 2003

FAPESP helped in meeting the publication costs of this article. 